\title{
Electrocatalytic $\mathrm{O}_{2}$ Reduction by an Organometallic Pd(III) Complex via a Binuclear Pd(III) Intermediate
}

Soumalya Sinha and Liviu M. Mirica*

Department of Chemistry, University of Illinois at Urbana-Champaign, Urbana, Illinois, 61801

*E-mail: mirica@illinois.edu

KEYWORDS. Organometallic $\mathrm{Pd}(\mathrm{III})$ complex, $\mathrm{O}_{2}$ reduction reaction (ORR), homogeneous electrocatalysis, heterogeneous electrocatalysis, second-order ORR kinetics

\section{ABSTRACT}

The development of electrocatalysts for the selective $\mathrm{O}_{2}-$ to- $\mathrm{H}_{2} \mathrm{O}$ conversion, the $\mathrm{O}_{2}$ reduction reaction (ORR), is of great interest for improving the performance of fuel cells. In this context, molecular catalysts that are known to mediate the $4 \mathrm{H}^{+} / 4 \mathrm{e}^{-}$reduction of $\mathrm{O}_{2}$ to $\mathrm{H}_{2} \mathrm{O}$ tend to be marred by limited stability and selectivity in controlling the multiproton and multielectron transfer steps. Thus, evaluation of new transition metal complexes, including organometallic species, for ORR reactivity could uncover new molecular catalysts with improved properties. We have previously reported the synthesis and characterization of various organometallic $\mathrm{Pd}^{\mathrm{III}}$ complexes stabilized by the tetradentate ligand N,N'-di-tert-butyl-2,11diaza[3.3] $(2,6)$ pyridinophane ( $\left.{ }^{\mathrm{B} u N 4}\right)$. These complexes were shown to react with $\mathrm{O}_{2}$ and undergo oxidatively-induced $\mathrm{C}-\mathrm{C}$ and $\mathrm{C}-$ heteroatom bond formation reactions in the presence of $\mathrm{O}_{2}$. These 
$\mathrm{O}_{2}$-induced oxidative transformations prompted us to evaluate the ORR reactivity of such organometallic Pd complexes, which to the best of our knowledge has never been studied before for any molecular Pd catalyst. Herein, we report the ORR reactivity of the $\left[\left({ }^{\mathrm{t}} \mathrm{BuN} 4\right) \mathrm{Pd}^{\mathrm{III}} \mathrm{MeCl}\right]^{+}$ complex, under both homogeneous and heterogeneous conditions in a non-aqueous and acidic aqueous electrolyte, respectively. Cyclic voltammetry and hydrodynamic electrochemical studies for $\left[\left({ }^{\mathrm{t}} \mathrm{BuN} 4\right) \mathrm{Pd}^{\mathrm{III}} \mathrm{MeCl}\right]^{+}$revealed the electrocatalytic reduction of $\mathrm{O}_{2}$ to $\mathrm{H}_{2} \mathrm{O}$ proceeds with Faradaic efficiencies (FE) of $50-70 \%$ in the presence of acetic acid $(\mathrm{AcOH})$ in $\mathrm{MeCN}$. The selectivity toward $\mathrm{H}_{2} \mathrm{O}$ production further improved to a $\mathrm{FE}$ of $80-90 \%$ in an acidic aqueous medium ( $\mathrm{pH}$ ), upon immobilization of the molecular catalyst onto edge plane graphite (EPG) electrodes. Analysis of electrochemical data suggests the formation of a binuclear $\mathrm{Pd}^{\mathrm{III}}$ intermediate in solution, likely a $\mathrm{Pd}^{\mathrm{III}}$-peroxo-Pd ${ }^{\mathrm{III}}$ species, which dictates the thermochemistry of the ORR process for $\left[\left({ }^{(} \mathrm{BuN} 4\right) \mathrm{Pd}^{\mathrm{III}} \mathrm{MeCl}\right]^{+}$in $\mathrm{MeCN}$, and thus being a rare example of a bimolecular ORR process. The maximum second-order turnover frequency $\mathrm{TOF}_{\max }^{(2)}=2.76 \times 10^{8}$ $\mathrm{M}^{-1} \mathrm{sec}^{-1}$ was determined for $0.32 \mathrm{mM}$ of $\left[\left({ }^{\mathrm{t}} \mathrm{BuN} 4\right) \mathrm{Pd}^{\mathrm{III}} \mathrm{MeCl}\right]^{+}$in the presence of $1 \mathrm{M} \mathrm{AcOH}$ in $\mathrm{O}_{2}$-saturated $\mathrm{MeCN}$ with an overpotential of $0.32 \mathrm{~V}$. By comparison, a comparatively lower $\mathrm{TOF}_{\max }{ }^{(2)}=1.25 \times 10^{5} \mathrm{M}^{-1} \sec ^{-1}$ at a higher overpotential of $0.8 \mathrm{~V}$ was observed for $\left[\left({ }^{\mathrm{t}} \mathrm{BuN} 4\right) \mathrm{Pd}^{\mathrm{III}} \mathrm{MeCl}\right] \mathrm{PF}_{6}$ adsorbed onto EPG electrodes in $\mathrm{O}_{2}$-saturated $1 \mathrm{M} \mathrm{H}_{2} \mathrm{SO}_{4}$ aqueous solution. Overall, reported herein is a detailed ORR reactivity study using a novel $\mathrm{Pd}^{\mathrm{III}}$ organometallic complex and benchmark its selectivity and energetics toward $\mathrm{O}_{2}$ reduction in $\mathrm{MeCN}$ and acidic aqueous solutions.

\section{INTRODUCTION}


Proton exchange membrane fuel cells (PEMFCs) that can store and convert chemical energy into electricity are practical and promising devices that can provide an alternative to the use of fossil fuels. ${ }^{1,2}$ A simple model of a PEMFC can be described as a two-compartment cell, with the cathodic and anodic chambers separated by a polymer electrolyte or proton exchange membrane (PEM). The anodic compartment splits $\mathrm{H}_{2}$ molecules into $2 \mathrm{H}^{+}$and $2 \mathrm{e}^{-}$, the protons being supplied to the cathodic compartment through the PEM, whereas the $\mathrm{e}^{-}$transfer occurs through the external circuit to balance the voltage difference. The cathodic compartment performs the $\mathrm{O}_{2}$ reduction reaction (ORR) by utilizing the provided protons and electrons to produce $\mathrm{H}_{2} \mathrm{O}^{3}$ However, the use of expensive Pt-based catalysts as both the anode and the cathode impedes the wide commercialization of such technologies. ${ }^{1,4}$ Therefore, a promising alternative to the $\mathrm{Pt}$ catalysts is highly desired. Although the development of cheap materials for water splitting or $\mathrm{H}_{2}$ oxidation has made significant progress, finding robust and cost-effective materials as cathode catalysts for ORR is still an ongoing challenge.,

Pd could be a choice to replace Pt because of its similarity in the crystal structure (facecentered cubic) and d-electronic configuration. ${ }^{7}$ In this regard, fuel cell relevant reactions, e.g., electrochemical $\mathrm{H}_{2}$ evolution or oxidation have shown progress by using Pd-based or carbonsupported Pd catalysts. ${ }^{8-10}$ Although pure metallic Pd is positioned very near to Pt in the volcano plot of ORR activity, as proposed by Nørskov and co-workers, ${ }^{11}$ its use for electrochemical ORR is either limited as an additive for the reduction of Pt loading ${ }^{12-14}$, while its reactivity is marred by the poor stability in acidic medium. ${ }^{15-17}$ In this regard, to the best of our knowledge, there is no Pd molecular catalyst that has been reported to date as a catalyst for the electrochemical ORR reaction. ${ }^{18}$ In the context of molecular ORR catalysts, metalloporphyrins bearing first-row transition metals (e.g., $\mathrm{Mn}, \mathrm{Fe}, \mathrm{Co}$ ) have gained immense attention. For example, $\mathrm{Mn}^{\mathrm{II}}$ 
tetraphenylporphyrin (MnTPP) and hangman porphyrin xanthene $\left(\mathrm{Mn}\left(\mathrm{HPX}-\mathrm{CO}_{2} \mathrm{H}\right)\right)$, reported by Nocera et al., reduces $\mathrm{O}_{2}$ with high selectivity, $\geq 75 \%$ toward $\mathrm{H}_{2} \mathrm{O}$ in $\mathrm{MeCN}$ in the presence of acetic acid $(\mathrm{AcOH})$ or its derivatives. ${ }^{19}$ Additional examples were provided by Mayer and coworkers for the homogeneous electrochemical ORR using different metalloporphyrin derivatives. ${ }^{18,20,21}$ Nevertheless, recent progress made to incorporate such metalloporphyrins into pyrolytic graphite electrodes also provide heterogeneous ORR platforms with high selectivity toward $\mathrm{H}_{2} \mathrm{O}$ production in an acidic aqueous medium that could have more impact for designing practical energy devices. ${ }^{22-24}$ However, the synthesis of porphyrins or its derivatives is often limited by low yields, which limits their potential industry-scale applications.

Thus, evaluation of new transition metal complexes, including organometallic species, for ORR reactivity could uncover new molecular catalysts with improved properties. We have previously reported the synthesis and characterization of various organometallic $\mathrm{Pd}^{\mathrm{III}}$ complexes stabilized by the tetradentate ligand N,N'-di-tert-butyl-2,11-diaza[3.3](2,6)pyridinophane ('BuN4) and related analogs. ${ }^{25-28}$ These complexes were shown to react with $\mathrm{O}_{2}$ and undergo oxidativelyinduced $\mathrm{C}-\mathrm{C}$ and $\mathrm{C}-$-heteroatom bond formation reactions in the presence of $\mathrm{O}_{2}$. These $\mathrm{O}_{2}$-induced oxidative transformations prompted us to evaluate the ORR reactivity of such organometallic complexes, which to the best of our knowledge has never been done before, for any molecular Pd catalyst. Herein, we report the ORR reactivity of the $\left[\left({ }^{\mathrm{t}} \mathrm{BuN} 4\right) \mathrm{Pd}^{\mathrm{III}} \mathrm{MeCl}\right] \mathrm{PF}_{6}$ complex, $\mathbf{1} \mathbf{P F}_{\mathbf{6}}$ (Figure 1), both under homogeneous and heterogeneous conditions in a non-aqueous and acidic aqueous electrolyte, respectively. Firstly, we benchmarked the electrocatalytic activity toward ORR using $\mathbf{1} \cdot \mathbf{P F}_{\mathbf{6}}$ in $\mathrm{MeCN}$ in the presence of $\mathrm{AcOH}$, and then the same catalyst was immobilized onto an edge plane graphite (EPG) electrode to compare its performance in $\mathrm{O}_{2}$-saturated $1 \mathrm{M}$ $\mathrm{H}_{2} \mathrm{SO}_{4}$ aqueous solution at $\mathrm{pH} 0$. Cyclic voltammetry and rotating-ring disk electrode voltammetry . $\mathrm{PF}_{6}$

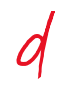


studies carried out for $\mathbf{1} \cdot \mathbf{P F} \mathbf{F}_{6}$ reveal high peak current density, $12 \mathrm{~mA} / \mathrm{cm}^{2}$ in $\mathrm{O}_{2}$-saturated $\mathrm{MeCN}$ with $1 \mathrm{M}$ of added $\mathrm{AcOH}$ and up to $70 \%$ selectivity for $\mathrm{H}_{2} \mathrm{O}$ formation. Additionally, interpretation of the electrochemical data and "foot-of-the-wave" analysis (FOWA) suggest the reaction mechanism for $\mathrm{O}_{2}$ reduction involves a binuclear $\mathrm{Pd}^{\mathrm{III}}$ intermediate, likely a $\mathrm{Pd}^{\mathrm{III}}$-peroxo-Pd ${ }^{\mathrm{III}}$ species. Second-order ORR rate constants $\left(k_{a p}\right)$ of $\sim 2.76 \times 10^{8} \mathrm{M}^{-1} \sec ^{-1}$ at different catalyst concentrations were also extracted using FOWA.
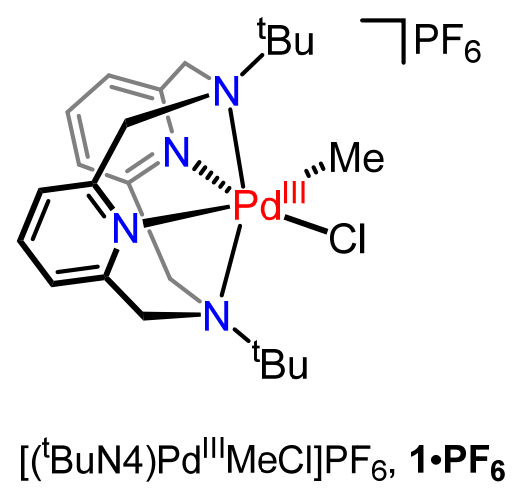

Figure 1. The organometallic $\mathrm{Pd}^{\mathrm{III}}$ complex employed herein in the ORR studies.

By comparison, electrochemical data obtained for $\mathbf{1} \cdot \mathbf{P F}_{\mathbf{6}}$ adsorbed onto EPG electrodes exhibited comparatively lower catalytic current densities, $0.5 \mathrm{~mA} / \mathrm{cm}^{2}$ but with high selectivity ( $\geq 80 \%$ ) toward $\mathrm{H}_{2} \mathrm{O}$ formation in $\mathrm{O}_{2}$-saturated $1 \mathrm{M}$ aqueous $\mathrm{H}_{2} \mathrm{SO}_{4}$. At these conditions, Koutecky-Levich (K-L) plots were also constructed, and the number of electrons associated with the heterogeneous ORR catalysis is estimated to be between 3.74 and 4.03 from the slope of the linearly fitted K-L plots within the applied potential of $0.2 \mathrm{~V}$ and $0.1 \mathrm{~V}$ vs. normal hydrogen electrode (NHE). Additionally, the intercepts of the linearly fitted K-L plots provided the overall second-order reaction rate constant as $1.25 \times 10^{5} \mathrm{M}^{-1} \mathrm{~s}^{-1}$ under these heterogeneous conditions. Overall, herein we report the ORR reactivity of an organometallic $\mathrm{Pd}^{\mathrm{III}}$ complex, and show that 
this species is an efficient and stable ORR electrocatalyst under both homogeneous and heterogeneous conditions in a non-aqueous and acidic aqueous electrolyte, respectively.

\section{EXPERIMENTAL DETAILS}

Reagents and Materials. All chemicals were commercially available from Aldrich, Fisher, or Strem Chemicals and were used as received without further purification. Solvents were purified prior to use by passing through a column of activated alumina using an MBraun solvent purification system.

\section{Synthesis and characterization}

Synthesis and detail characterization of $\left[\left({ }^{\mathrm{t}} \mathrm{BuN} 4\right) \mathrm{Pd}^{\mathrm{III}} \mathrm{MeCl}\right] \mathrm{PF}_{6}, \mathbf{1} \cdot \mathbf{P F}$, was reported previously. ${ }^{25}$

\section{Electrochemical Studies}

All electrochemical experiments were carried out using BASi Epsilon and $\mathrm{CH}$ Instruments potentiostats. Rotating ring-disk electrochemistry (RRDE) used glassy carbon as the disk and Ptwire as the ring electrode, and all RRDE experiments were performed using the Pine Modulated Speed Rotator. All cyclic voltammograms (CVs) and RRDE data are plotted according to the "US convention" 29 , where the positive and negative currents are for the reduction and oxidation processes, respectively. All CVs were recorded at $0.1 \mathrm{~V} / \mathrm{s}$ scan rate unless otherwise noted.

Homogeneous electrochemical studies. Cyclic voltammetry was carried out using a conventional three-electrode cell with a glassy carbon (GC) working electrode (surface area $=0.07 \mathrm{~cm}^{2}$ ), nonaqueous $\mathrm{Ag} / 0.01 \mathrm{M} \mathrm{AgNO}_{3}$ in $\mathrm{MeCN}$ reference electrode, and Pt-wire counter electrode. The GC electrode was prepared by polishing on a cloth polishing pad using 5-micron aluminum oxide polishing slurry, followed by a thorough deionized water rinse, and gently drying with a heat gun. ${ }^{29}$ 
CVs were recorded by dissolving 1 to $1.5 \mathrm{mM}$ concentration with $0.1 \mathrm{M}^{n} \mathrm{Bu}_{4} \mathrm{NPF}_{6}\left(\mathrm{TBAPF}_{6}\right)$ in dry $\mathrm{MeCN}$, unless otherwise noted. Ferrocene was used as an external standard, and all potentials were reported with respect to the ferrocenium-ferrocene couple $\left(\mathrm{Fc}^{+/ 0}\right) \cdot{ }^{30}$

Heterogeneous electrochemical studies. Cyclic voltammetry was carried out using a conventional three-electrode cell with an edge plane graphite $(\mathrm{EPG})$ working electrode (surface area $=0.09$ $\mathrm{cm}^{2}$ ), aqueous $\mathrm{AgCl} / \mathrm{Ag}$ reference electrode, and a carbon rod or $\mathrm{GC}$ counter electrode. The EPG electrodes were polished and prepared following literature procedures. ${ }^{22,23}$ A $20 \mu \mathrm{L}$ aliquot of 1.5 $\mathrm{mM} 1$ in MeCN was drop-cast onto the EPG working electrode, dried to evaporate the solvent residues, and rinsed thoroughly with deionized water to remove any loosely bound molecules on the electrode surface. All heterogeneous electrochemical experiments were studied in $1 \mathrm{M} \mathrm{H}_{2} \mathrm{SO}_{4}$ aqueous solution at $\mathrm{pH} 0$ either after saturating in the $\mathrm{N}_{2}$ or $\mathrm{O}_{2}$ atmosphere. All potentials for heterogeneous electrochemical experiments were reported with respect to the normal hydrogen electrode (NHE).

\section{RESULTS AND DISCUSSION}

\section{Homogeneous Electrochemical ORR Studies}

\section{CV studies under $\mathrm{N}_{2}$}

The initial electrochemical studies were performed under $\mathrm{N}_{2}$ by dissolving $\left[\left({ }^{\mathrm{t} B u N 4}\right) \mathrm{Pd}^{\mathrm{III}} \mathrm{MeCl}\right] \mathrm{PF}_{6}, \mathbf{1} \cdot \mathrm{PF}_{6}$, in $0.1 \mathrm{M} \mathrm{TBAPF} / \mathrm{MeCN}$. Cyclic voltammograms (CVs) recorded

for 1 showed a reversible wave centered at $0.58 \mathrm{~V}$ vs. $\mathrm{Fc}^{+/ 0}$ for the $\mathrm{Pd}^{\mathrm{III} / \mathrm{V}}$ redox couple and an irreversible redox wave at $-0.45 \mathrm{~V}$ vs. $\mathrm{Fc}^{+/ 0}$ (Figure 2), assigned to the reduction of $\mathrm{Pd}^{\mathrm{III}}$ to $\mathrm{Pd}^{\mathrm{II}}$ based on our previous reports. ${ }^{25} \mathrm{In}$ addition, a small anodic wave at $0.14 \mathrm{~V}$ vs. $\mathrm{Fc}^{+/ 0}$ appeared upon 
repeating the $\mathrm{CV}$ sweeps, indicating the oxidation of a small amount of $\mathrm{Pd}^{\mathrm{II}}$ formed during the reductive scans. ${ }^{25}$ However, successive $\mathrm{CV}$ cycles recorded for $\mathbf{1}$ in $\mathrm{MeCN}$ under $\mathrm{N}_{2}$ showed stable peak currents for these redox features (Figure 2).

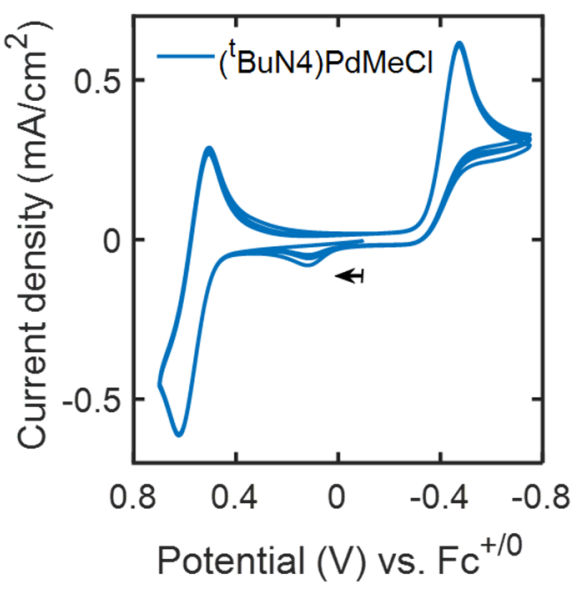

Figure 2. CVs recorded for 1 in $\mathrm{N}_{2}$-saturated $0.1 \mathrm{M} \mathrm{TBAPF} / \mathrm{MeCN}_{6}$ upon four repeating $\mathrm{CV}$ sweeps at the scan rate of $0.1 \mathrm{~V} / \mathrm{s}$. The black arrow shown in the figure indicates the scan direction.

CVs were also collected for 1 in $\mathrm{N}_{2}$-saturated $\mathrm{MeCN}$ at different scan rates $(v=0.1 \mathrm{~V} / \mathrm{s}-$ $1 \mathrm{~V} / \mathrm{s}$, Figure $3 \mathrm{a}$ ), and a linearity in the cathodic peak currents $\left(i_{p c}\right)$ for the $\mathrm{Pd}^{\mathrm{III} / \mathrm{VV}}$ redox couple was observed with the square root of the scan rate $(\sqrt{v})$ (Figure 3b) that signifies free diffusive homogeneous processes with no significant adsorption or deposition of molecules onto the electrode surface during the $\mathrm{CV}$ cycles. ${ }^{29}$ This uncommon stability of a Pd complex under reducing conditions and the lack of any Pd metal deposition onto the cathode is unique and likely due to the hard donor atoms of the ${ }^{\mathrm{t}} \mathrm{BuN} 4$ ligand and the presence of an organic methyl ligand that severely destabilize the low oxidation states of the Pd center. The slope of the linear fit obtained by plotting the cathodic peak currents, $i_{p c}$ observed for Pd ${ }^{\mathrm{III} / \mathrm{V}}$ redox waves at different scan rates provided the diffusion coefficient (D) as $1.9 \times 10^{-6} \mathrm{~cm}^{2} \mathrm{~s}^{-1}$ by using the Eq. (1), ${ }^{19,31}$ 


$$
i_{p c}=0.446 F S C \sqrt{\frac{F}{R T}} \sqrt{D} \sqrt{v} ;
$$

where $\mathrm{S}$ is the electrode surface area $\left(=0.07 \mathrm{~cm}^{2}\right), \mathrm{C}$ is the concentration of $\mathbf{1}(1.5 \mathrm{mM}), \mathrm{F} / \mathrm{RT}=$ 38.94 $\mathrm{V}^{-1}$ in which $\mathrm{F}$ is the Faraday constant, $\mathrm{R}$ is the universal gas constant, and $\mathrm{T}$ is the temperature.

(a)
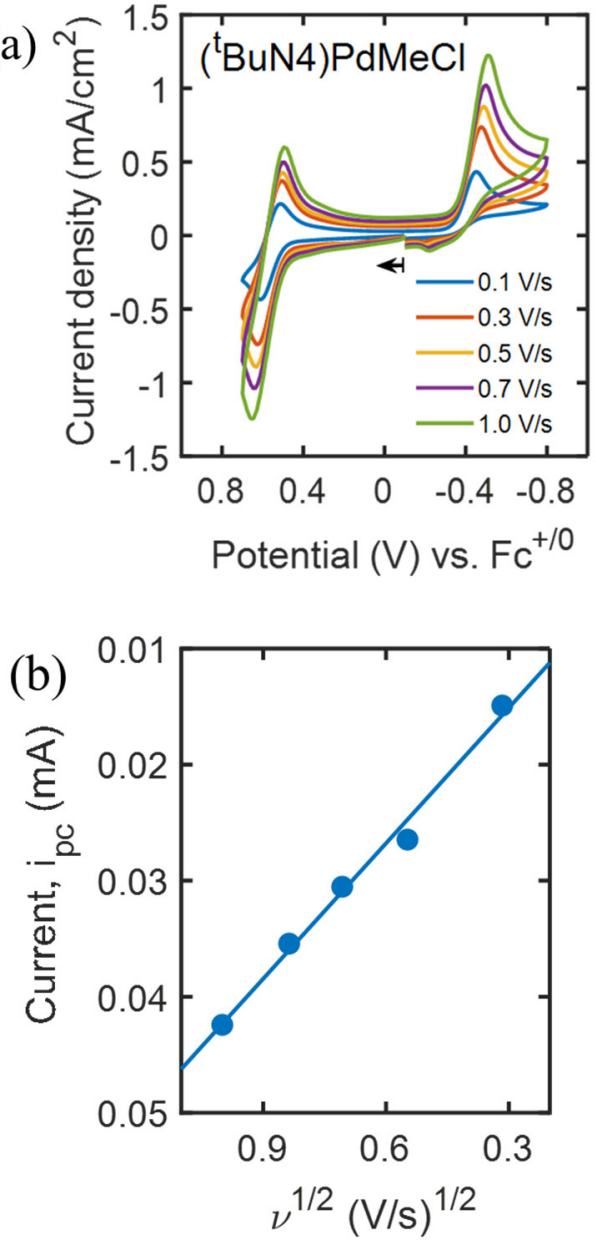

Figure 3. (a) CVs recorded for $\mathbf{1}$ in $\mathrm{N}_{2}$-saturated $\mathrm{MeCN}$ at different scan rates $(0.1 \mathrm{~V} / \mathrm{s}-1 \mathrm{~V} / \mathrm{s})$. (b) The linear fit for cathodic peak currents $\left(i_{p c}\right)$ obtained at $\mathrm{Pd}^{\mathrm{III} / \mathrm{IV}}$ redox couple at different scan rates with the square root of the scan rate $\left(v^{1 / 2}\right)$. The $\mathrm{R}^{2}$ value for the linear fit is 0.99 .

The electrochemical stability of $\mathbf{1}$ under acidic conditions was then tested by recording CVs in the presence of $\mathrm{AcOH}$ at different concentrations from $0.1 \mathrm{M}$ and $1 \mathrm{M}$ in $\mathrm{N}_{2}$-saturated $\mathrm{MeCN}$. Under these electrochemical conditions, the CVs did not show any changes of the peak 
potentials or degradation in peak currents, as compared to those observed in the absence of the acid (Figure 4a). Additionally, the stability of 1 was also investigated by adding $1 \mathrm{M}$ of trifluoroacetic acid (TFA) or $\mathrm{MeOH}$ in $\mathrm{MeCN}$, and no prominent changes in the $\mathrm{CV}$ sweeps were observed (Figure S6 and Figure S7). Furthermore, the UV-vis absorption spectra of 1 in $\mathrm{MeCN}$ in the presence of different amounts of AcOH did not show any significant changes of the UV-vis spectra (Figure $4 \mathrm{~b}$ ). Together, these results suggest that $\mathbf{1}$ is impressively stable in the presence of moderate to weak acids in $\mathrm{MeCN}$, and the chelating amine arms of the ${ }^{\mathrm{t}} \mathrm{BuN} 4$ ligand in $\mathbf{1}$ do not easily get protonated. ${ }^{25}$
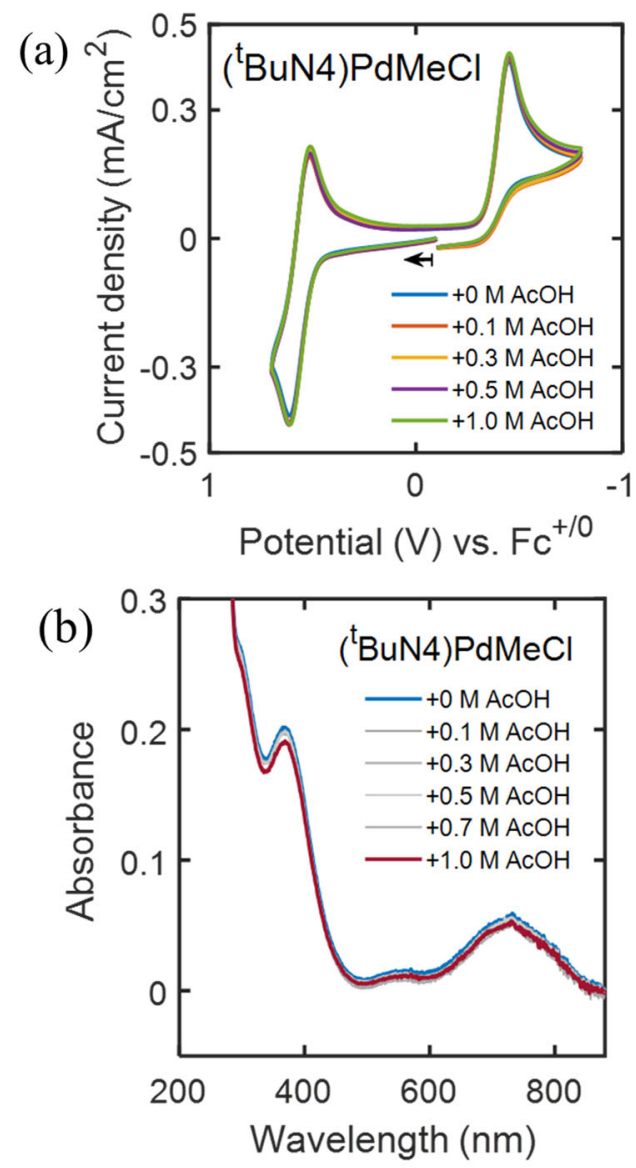

Figure 4. (a) CVs recorded for 1 in $\mathrm{N}_{2}$-saturated $0.1 \mathrm{M} \mathrm{TBAPF}_{6} \mathrm{MeCN}$ in the absence and presence of different amount of $\mathrm{AcOH}(0.1 \mathrm{M}-1.0 \mathrm{M})$. (b) Absorption spectra for $\mathbf{1}$ in $\mathrm{MeCN}$ in the absence and presence of $\mathrm{AcOH}$ up to $1 \mathrm{M}$. 


\section{Homogeneous electrochemical ORR in the presence of $\mathrm{AcOH}$}

The CVs of 1 in $\mathrm{O}_{2}$-saturated $\mathrm{MeCN}$ showed a slight increase in current densities at the peak potential of the $\mathrm{Pd}^{\mathrm{III} / \mathrm{II}}$ reductive wave, indicating a small degree of $\mathrm{O}_{2}$ reduction in dry $\mathrm{MeCN}$ (Figure 5a). An additional current enhancement beyond $-1 \mathrm{~V}$ vs. $\mathrm{Fc}^{+/ 0}$ was also observed and that overlapped with the background activity of the bare GC electrode under identical electrochemical conditions (Figures $\mathrm{S} 1$ and S9). However, the addition of $1 \mathrm{M} \mathrm{AcOH}$ into the $\mathrm{O}_{2}$-saturated $\mathrm{MeCN}$ solution of 1 moved the peak potential of the $\mathrm{Pd}^{\mathrm{III} / \mathrm{II}}$ couple toward more positive potentials, and catalytic currents near the $\mathrm{Pd}^{\mathrm{III} / \mathrm{II}}$ redox wave were observed (Figure 5c). A catalytic peak current density of $12 \mathrm{~mA} / \mathrm{cm}^{2}$ was measured at a potential of $-1.39 \mathrm{~V} \mathrm{vs}$. $\mathrm{Fc}^{+/ 0}$ for the $\mathrm{O}_{2}$-saturated $\mathrm{MeCN}$ solution of 1 in the presence of $1 \mathrm{M} \mathrm{AcOH}$ (Figure 5b, orange line), and this current density is comparatively higher and occurs at a less negative potential than those observed for the GC electrode in the absence of $\mathbf{1}$ (Figure S2). A control experiment carried out for $\mathbf{1}$ in $\mathrm{N}_{2}$-sparged $\mathrm{MeCN}$ in the presence of $1 \mathrm{M} \mathrm{AcOH}$ revealed that the onset potential of the background proton reduction happens at a $\sim 400 \mathrm{mV}$ lower potential compared to the $\mathrm{CV}$ obtained for the same solution in the presence of $\mathrm{O}_{2}$ (Figure $5 \mathrm{~b}$, blue dotted line). 

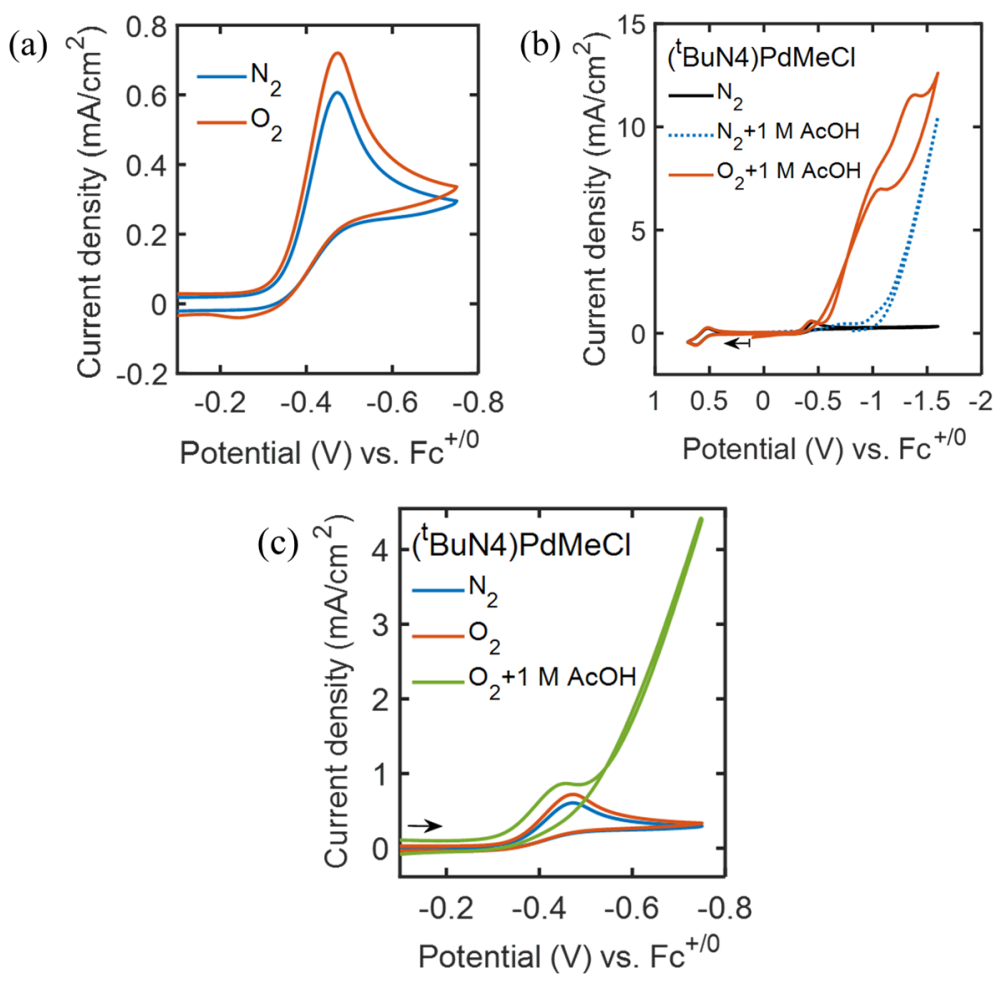

Figure 5. (a) Comparative CVs recorded for 1 in $\mathrm{N}_{2}$ - (blue) and $\mathrm{O}_{2}$-saturated (orange) $0.1 \mathrm{M}$ $\mathrm{TBAPF}_{6} / \mathrm{MeCN}$. (b) Same as (a) but in the presence of $1 \mathrm{M} \mathrm{AcOH}$ within the electrochemical window between $0.8 \mathrm{~V}$ and $-1.6 \mathrm{~V}$ vs. $\mathrm{Fc}^{+/ 0}$. (c) Same as (a) but after the addition of $1 \mathrm{M} \mathrm{AcOH}$ in $\mathrm{O}_{2}$-saturated $\mathrm{MeCN}$. All CVs were recorded at $0.1 \mathrm{~V} / \mathrm{s}$ scan rate.

Interestingly, when the CV sweep was reversed after completing a reductive forward scan up to the potential of $-1.6 \mathrm{~V}$ vs. $\mathrm{Fc}^{+/ 0}$, the return wave showed a hysteretic crossing of the forward wave in $\mathrm{O}_{2}$-sparged $\mathrm{MeCN}$ in the presence of $1 \mathrm{M} \mathrm{AcOH}$ (Figure 6a). Such hysteresis behavior was more prominent at low scan rates $(\leq 0.1 \mathrm{~V} / \mathrm{s})$, but disappeared at high scan rates $(\geq 2 \mathrm{~V} / \mathrm{s}$, Figure $6 \mathrm{~b}$ ). It is noteworthy to mention that a similar hysteretic electrochemical crossing has also been observed as the formation of a binuclear $\mathrm{Pd}^{\mathrm{III}}$ species during the methane oxidation process. ${ }^{32}$ Besides, CVs recorded for 1 using $1 \mathrm{M} \mathrm{AcOH}$ showed that the catalytic redox waves moved toward more positive potentials upon repeating $\mathrm{CV}$ cycles in the presence of $\mathrm{O}_{2}$ (Figure $\mathrm{S} 12$ ). We hypothesize that these changes are due to the formation of thermodynamically favorable intermediates during ORR in the first CV sweep that could re-enter the next catalytic cycle of ORR 
events in the consecutive CV sweeps. Further discussion of the possible ORR mechanism for $\mathbf{1}$ is included below.
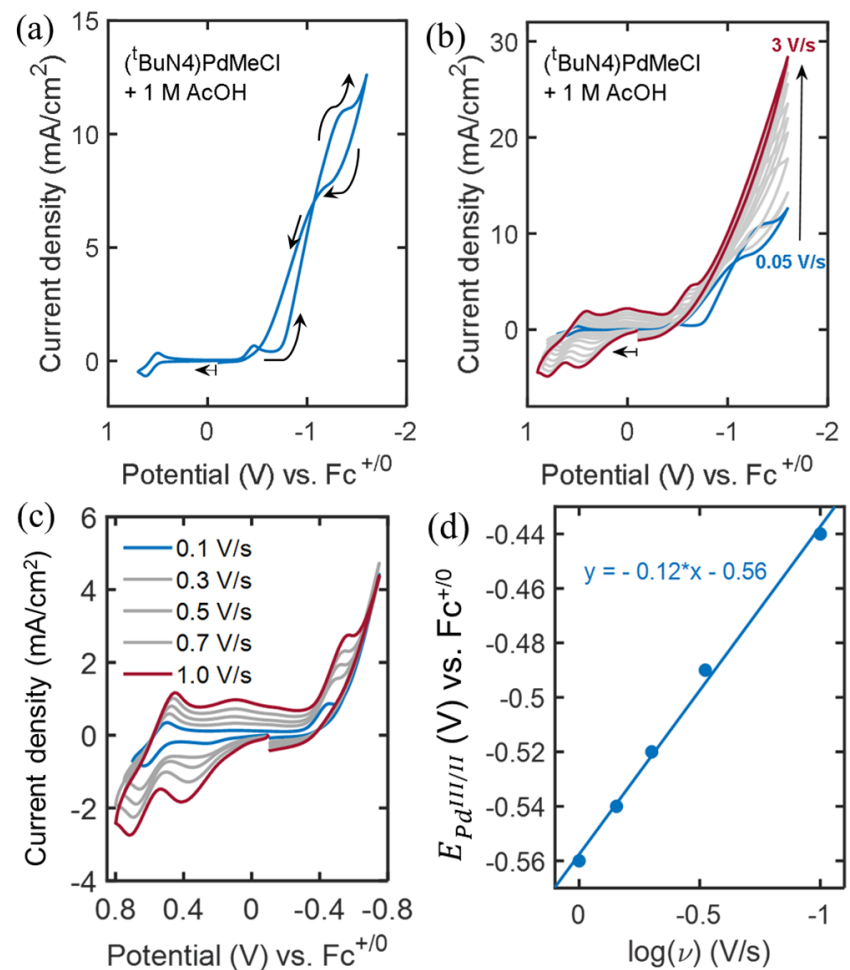

Figure 6. $\mathrm{CVs}$ recorded for 1 in $\mathrm{O}_{2}$-saturated $\mathrm{MeCN}+1 \mathrm{M} \mathrm{AcOH}$ at (a) the scan rate of $0.05 \mathrm{~V} / \mathrm{s}$, (b) different scan rates $(0.05 \mathrm{~V} / \mathrm{s}-3 \mathrm{~V} / \mathrm{s})$, (c) different scan rates $(0.1 \mathrm{~V} / \mathrm{s}-1 \mathrm{~V} / \mathrm{s})$ but within the electrochemical window between $0.8 \mathrm{~V}$ and $-0.8 \mathrm{~V} \mathrm{vs} . \mathrm{Fc}^{+/ 0}$. (d) The linear fit obtained for cathodic peak potentials at $\mathrm{Pd}^{\mathrm{III} / \mathrm{II}}$ redox couple at different scan rates from (c) with the logarithm of the scan rate. The $\mathrm{R}^{2}$ value for the linear fit is 0.99 .

Additionally, new redox features around $0.4 \mathrm{~V}$ vs. $\mathrm{Fc}^{+/ 0}$ under the conditions mentioned above were observed and they became more reversible as the scan rate was increased (Figures $6 \mathrm{~b}$ and 6c). The appearance of these new redox waves near the $\mathrm{Pd}^{\mathrm{III/V}}$ redox couple could be indicative of the formation of another $\mathrm{Pd}^{\mathrm{III}}$ species in solution. Such new redox features were also consistent with a similar set of CVs obtained within the electrochemical window between $0.8 \mathrm{~V}$ and $-0.8 \mathrm{~V}$ vs. $\mathrm{Fc}^{+/ 0}$ (Figure 6c). However, the potentials obtained at the $\mathrm{Pd}^{\mathrm{III/II}}$ reductive waves at the different scan rates exhibited a linear correlation vs. the scan rate with a slope of $120 \mathrm{mV} / \mathrm{decade}$ (Figure 6d), suggesting a faster proton-coupled electron transfer (PCET) process. ${ }^{33}$ Further ORR reactivity 
studies were performed for $\mathbf{1}$ using three different Brönsted acids, TFA ( $\left.\mathrm{p} K_{\mathrm{a}}=12.65\right),{ }^{34}, \mathrm{AcOH}$ $\left(\mathrm{p} K_{\mathrm{a}}=23.51\right),{ }^{34}$ and $\mathrm{MeOH}\left(\mathrm{p} K_{\mathrm{a}}=37.44\right)^{35}$ at $1 \mathrm{M}$ in $\mathrm{MeCN}$, and they revealed that the onset potentials of the catalytic waves maintained a correlation of $51 \mathrm{mV}$ per $\mathrm{p} K_{\mathrm{a}}$ unit of the acid used, also suggesting a Nernstian behavior corresponding to a concerted PCET process (Figures 7a and 7b). ${ }^{36}$
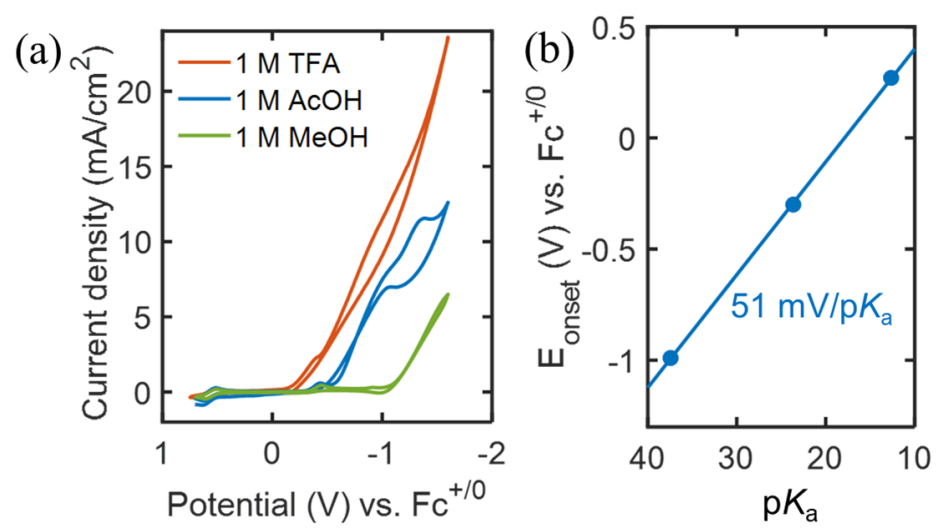

Figure 7. (a) $\mathrm{CVs}$ collected for 1 in $\mathrm{O}_{2}$-saturated $\mathrm{MeCN}$ in the presence of $1 \mathrm{M}$ concentration of TFA (orange), AcOH (blue), and $\mathrm{MeOH}$ (green). (b) Onset potentials, Eonset (V) obtained from (a) plotted versus the $\mathrm{p} K_{\mathrm{a}}$ values of the corresponding acid in $\mathrm{MeCN}$.

\section{Rotating-ring disk electrode (RRDE) voltammetry for homogeneous ORR}

In order to benchmark the selectivity of the homogeneous ORR, we performed RRDE experiments in $\mathrm{O}_{2}$-saturated $\mathrm{MeCN}$ in the presence of $1 \mathrm{M} \mathrm{AcOH}$ by following the methods as described by Nocera and co-workers. ${ }^{19}$ For these measurements, we used a low concentration of $\mathbf{1}$ $(0.5 \mathrm{mM})$ to maintain an overall pseudo-first order reaction with respect to the dissolved $\mathrm{O}_{2}$ concentration $(\sim 8.1 \mathrm{mM}$ in $\mathrm{MeCN}) .{ }^{19}$. However, under such electrochemical conditions, 1 exhibited quasi-limiting disk currents at the potentials between $-1.2 \mathrm{~V}$ and $-1.6 \mathrm{~V}$ vs. Fc ${ }^{+/ 0}$ (Figure 8a). The Faradaic efficiency (FE) for $\mathrm{H}_{2} \mathrm{O}$ was then estimated using the following equation, Eq. $(2):{ }^{19,23}$ 


$$
100-\% \mathrm{H}_{2} \mathrm{O}_{2}=100-\left(\frac{2 \times{ }^{I_{r}} /{ }_{N}}{I_{d}+{ }^{I_{r}} / N} \times 100\right) ; \quad \text { Eq. (2) }
$$

where $I_{d}$ is the disk current, $I_{r}$ is the ring current, and $\mathrm{N}$ is the collection efficiency $(=0.18)$. The maximum $\mathrm{FE}$ for $\mathrm{H}_{2} \mathrm{O}$ using 1 was thus obtained as $\sim 70 \%$ within the applied potentials nearer to the onset potentials, between $-0.5 \mathrm{~V}$ and $-1 \mathrm{~V}$ vs. $\mathrm{Fc}^{+/ 0}$ (Figure $8 \mathrm{~b}$ ). However, the $\mathrm{FE}$ for $\mathrm{H}_{2} \mathrm{O}$ was further degraded down to $\sim 50 \%\left(50 \% \mathrm{H}_{2} \mathrm{O}_{2}\right)$ at potentials between $-1 \mathrm{~V}$ and $-1.4 \mathrm{~V}$ vs. $\mathrm{Fc}^{+/ 0}$, while the ORR activity beyond $-1.5 \mathrm{~V}$ vs. $\mathrm{Fc}^{+/ 0}$ includes the background ORR contribution from the bare GC disk electrode.
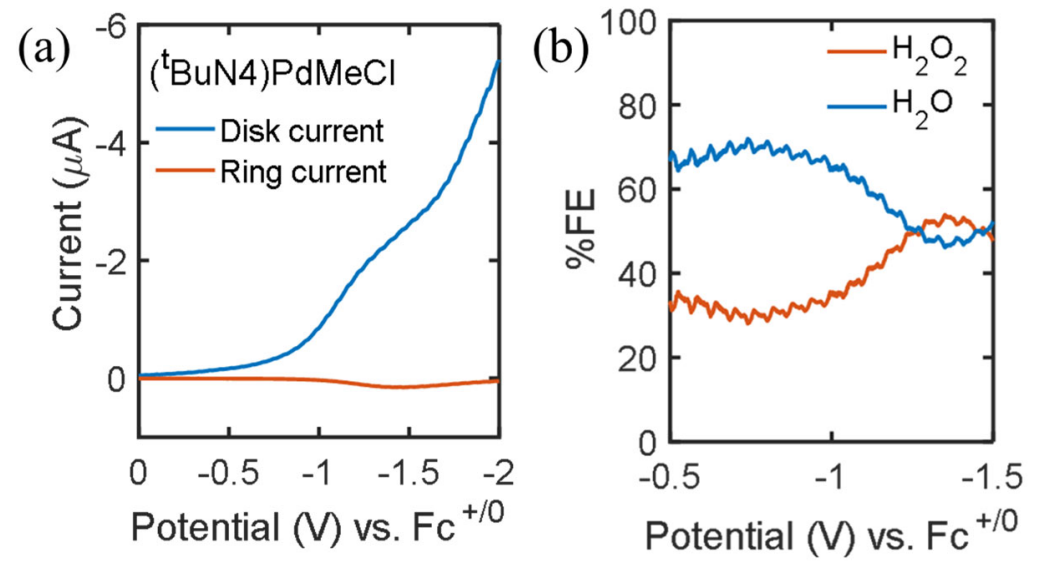

Figure 8. (a) RRDE data for $1(0.5 \mathrm{mM})$ in $\mathrm{O}_{2}$-saturated $0.1 \mathrm{M} \mathrm{TBAPF}_{6} \mathrm{MeCN}+1 \mathrm{M} \mathrm{AcOH}$ at the rotation rate of $150 \mathrm{rpm}$. Scan rate $=0.02 \mathrm{~V} / \mathrm{s}$. The potential at the Pt-ring was held at $1 \mathrm{~V}$ vs. reference electrode. (b) Faradaic efficiencies in percentage $(\% \mathrm{FE})$ for $\mathrm{H}_{2} \mathrm{O}_{2}$ and $\mathrm{H}_{2} \mathrm{O}$ obtained from the data, as shown in (a) by using Eq. (2).

\section{Investigation of the ORR mechanism in MeCN in the presence of $\mathrm{AcOH}$}

Based on our electrochemical data and literature reports, we propose an overall electrochemical mechanism for ORR for the organometallic Pd ${ }^{\mathrm{III}}$ complex $\mathbf{1}$ as outlined in scheme 1. The catalytic cycle begins upon the $1 \mathrm{e}^{-}$reduction of $\mathbf{1}$ to form ( $\left.{ }^{\mathrm{t}} \mathrm{BuN} 4\right) \mathrm{Pd}^{\mathrm{II}} \mathrm{MeCl}(\mathbf{2})$, which can 
react with $\mathrm{O}_{2}$, as the slight increase in the current densities was observed at the redox couple of $\mathrm{Pd}^{\mathrm{III} / \mathrm{II}}$ in dry MeCN (Figure 5a). The adduct formed after the $\mathrm{O}_{2}$ binding at the $\mathrm{Pd}^{\mathrm{II}}$ center can be described as a Pd ${ }^{\mathrm{III}}$-superoxide complex $(3),{ }^{26}$ which then can undergo a faster PCET process in the presence of an acid to yield complex 4 in the pre-catalytic ORR step. The appearance of a new quasi-reversible redox wave prior to the reversible $\mathrm{Pd}^{\mathrm{III/IV}}$ redox couple in the presence of $\mathrm{O}_{2}$ and acid suggests the formation of a new high valent Pd species (Figures 6b-6c) that can be tentatively assigned to a binuclear $\mathrm{Pd}^{\mathrm{III}}$-peroxo-Pd ${ }^{\mathrm{III}}$ complex (5) as a result of the reaction between complexes 4 and excess 1 in the bulk electrolyte. Thus, the appearance of two redox couples within the electrochemical window between 0 and $0.8 \mathrm{~V}$ vs. $\mathrm{Fc}^{+/ 0}$ in the presence of $\mathrm{O}_{2}$ and $\mathrm{AcOH}$ could be ascribed as sequential $1 \mathrm{e}^{-}$redox events for the two $\mathrm{Pd}^{\mathrm{III}}$ centers of complex $\mathbf{5}$, in line with what was reported previously for binuclear Pd ${ }^{\mathrm{III}}$ complexes that exhibit similar CVs. ${ }^{37}$

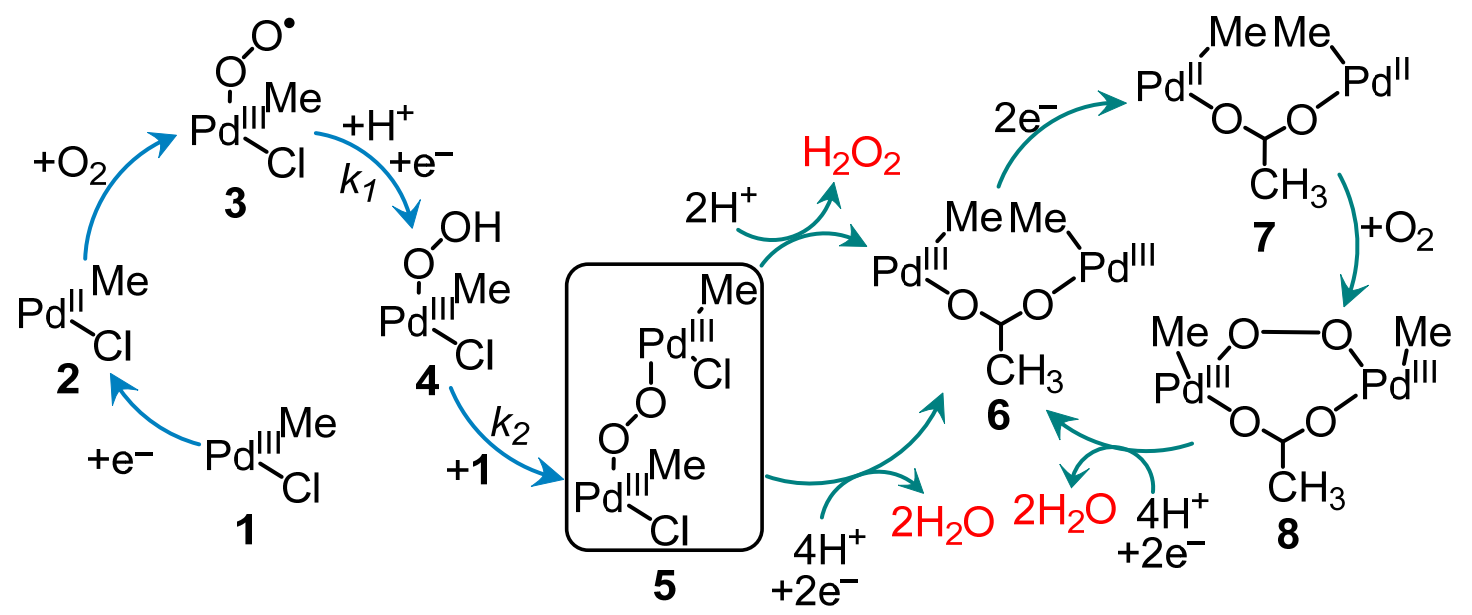

Scheme 1. The proposed mechanism for ORR using 1 in $\mathrm{O}_{2}$-saturated $\mathrm{MeCN}$ in the presence of 1 $\mathrm{M} \mathrm{AcOH}$. The chelating ${ }^{\mathrm{t}} \mathrm{BuN} 4$ ligand is omitted for clarity. An alternate ORR catalytic mechanism could involve binuclear Pd complexes in which the two Pd centers are not bridged by an acetate group, similar to intermediate 5 .

The proposed binuclear $\mathrm{Pd}^{\mathrm{III}}$-peroxo-Pd ${ }^{\mathrm{III}}$ intermediate $\mathbf{5}$ is sensitive to the acid concentration and generates $\mathrm{H}_{2} \mathrm{O}_{2}$ with a maximum $\mathrm{FE}$ of $30 \%$, as observed in the RRDE 
experiments at potentials between the onset potential and $-1.0 \mathrm{~V}$ vs. $\mathrm{Fc}^{+/ 0}$. However, within these applied potentials, $\mathrm{H}_{2} \mathrm{O}$ was obtained as the major product at the beginning of the ORR process, and hence, we propose that complex 5 also can be reduced by $4 \mathrm{H}^{+}$and $2 \mathrm{e}^{-}$to form two molecules of $\mathrm{H}_{2} \mathrm{O}$ and complex 6 . We propose that complex 6 is most likely a binuclear $\mathrm{Pd}^{\mathrm{III}}$ complex bridged with an acetate residue after replacing ligated $\mathrm{Cl}^{-}$ions in the presence of high $\mathrm{AcOH}$ concentration in $\mathrm{O}_{2}$-saturated $\mathrm{MeCN}$, although a mononuclear $\mathrm{Pd}^{\mathrm{III}} \mathrm{Me}(\mathrm{OAc})$ complex cannot be excluded. Further reductive scanning in the forward CV sweep during the ORR process could lead to a $2 \mathrm{e}^{-}$ reduction of 6 to yield the $\mathrm{Pd}^{\mathrm{II}}$ complex 7, which should also be able to interact with $\mathrm{O}_{2}$ and thus start a new catalytic ORR cycle. The reaction of 7 with $\mathrm{O}_{2}$ could generate a binuclear $\mathrm{Pd}^{\mathrm{III}}$-peroxo$\mathrm{Pd}^{\mathrm{III}}$ complex 8, which could undego a $4 \mathrm{H}^{+} / 2 \mathrm{e}^{-}$reduction event to generate water and complex $\mathbf{6}$, and thus closing the catalytic ORR cycle. The participation of complex 6 into the next ORR cycle is expected to shift the catalytic wave toward more positive potential (or less overpotential) upon repeating $\mathrm{CV}$ cycles (Figure S12). In addition, an alternate ORR catalytic mechanism could be envisioned that involves binuclear Pd species similar to 6, 7, and 8, yet in which the two Pd centers are not bridged by an acetate group, analogous to species $\mathbf{5}$.

\section{Foot-of-the-wave analysis (FOWA) and reaction orders for ORR catalysis}

FOWA was carried out to gain kinetic insights of the ORR process for 1 . In $\mathrm{O}_{2}$-saturated $\mathrm{MeCN}, 1$ showed quasi-plateau current densities at different concentrations of $\mathrm{AcOH}$ between 0.3 $\mathrm{M}$ and 1.0 M (Figure S13). These CVs were then fitted using the FOWA equation (Figure 9a and Figures S16-S19), and the slopes obtained from the FOWA provided the pseudo-first order reaction rate constants $\left(k_{1}\right)$ that can be considered as the maximum turnover frequency at a given acid concentration (Table S1). ${ }^{35}$ The logarithms of these $k_{1}$ values were then plotted versus the 
logarithm of $\mathrm{AcOH}$ concentration and fitted linearly (Figure 9b), and the slope obtained from the linear fit suggests a first-order reaction with respect to the acid concentration when the concentrations of catalyst $\mathbf{1}(1.5 \mathrm{mM})$ and $\mathrm{O}_{2}(8.1 \mathrm{mM}$ in $\mathrm{MeCN})$ were held constant. Such firstorder reaction indicates that the first protonation step at the $\mathrm{Pd}^{\mathrm{III}}$-superoxide complex (3) involves one equiv of $\mathrm{AcOH}$ that drives the reaction to form the $\mathrm{Pd}^{\mathrm{III}}$-hydroperoxo intermediate 4 (Scheme 1).
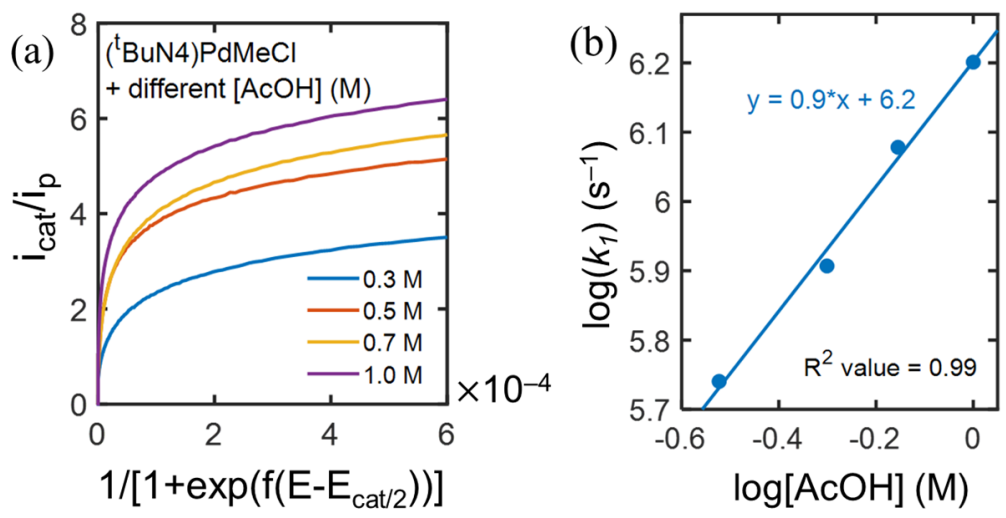

Figure 9. (a) Fitting of FOWA equation for the $\mathrm{CVs}$ of $\mathbf{1}$ in $\mathrm{O}_{2}$-saturated $\mathrm{MeCN}$ in the presence of different concentration of $\mathrm{AcOH}, 0.3 \mathrm{M}$ (blue), $0.5 \mathrm{M}$ (orange), $0.7 \mathrm{M}$ (yellow), and $1.0 \mathrm{M}$ (purple). ${ }^{35}$ (b) Plot for the logarithm of $k_{1}$, as estimated from the FOWA versus the logarithm of $\mathrm{AcOH}$ concentration and fitted linearly. The slope of the linear fit, 0.9, indicates the first-order rate constant with respect to the acid concentration.

Similarly, keeping the concentration of $\mathrm{AcOH}(1.0 \mathrm{M})$ constant in $\mathrm{O}_{2}$-saturated $\mathrm{MeCN}$, CVs recorded at low concentrations of $1(0.12 \mathrm{mM}, 0.17 \mathrm{mM}, 0.22 \mathrm{mM}$, and $0.32 \mathrm{mM})$ showed that the onset potential moved toward more positive potential with a slight increase in the quasilimiting currents as the catalyst concentration was increased (Figure S14). The apparent reaction rate constants $\left(k_{a p}\right)$ was estimated under these conditions using a modified FOWA equation (Eq. $\mathrm{S} 5$ and Table S2) ${ }^{35,38}$ and variation of $k_{a p}$ was then fitted linearly with the varying concentration of catalysts, and the slope of the linear fit was determined to be $\sim 1.7$, thus suggesting an ORR reaction that is second-order with respect to the catalyst (Figure 10). A similar second order ORR 
reaction was observed for an iron-porphyrin catalyst where a peroxo-bridged $\mathrm{Fe}^{\mathrm{III}}$ porphyrin dimer becomes a key intermediate toward $\mathrm{H}_{2} \mathrm{O}_{2}$ formation. ${ }^{39}$ Moreover, the second-order dependence of the reaction on the catalyst concentration also supports our proposal for the formation of a binuclear Pd intermediate, most likely a binuclear Pd ${ }^{\mathrm{III}}$-peroxo-Pd ${ }^{\mathrm{III}}$ species (5).
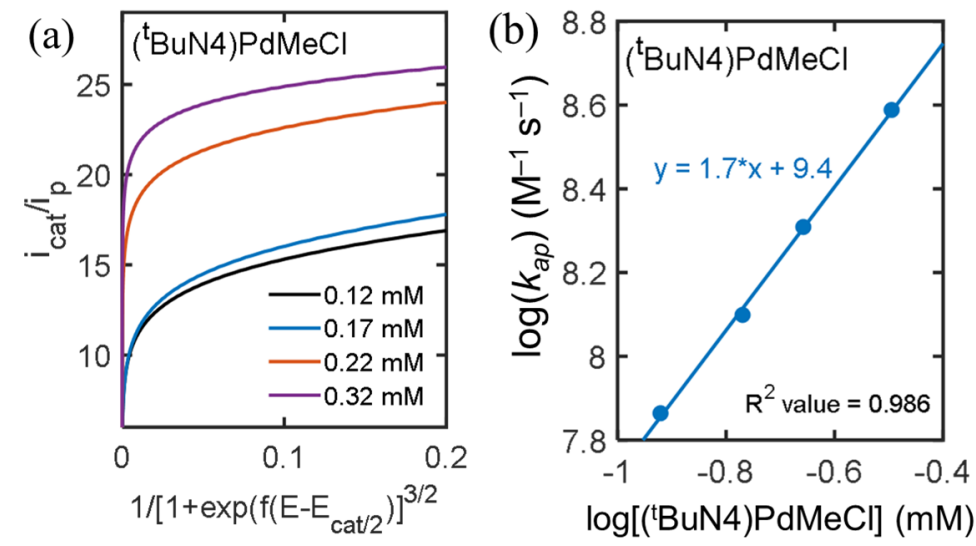

Figure 10. (a) Fitting of FOWA equation for the CVs of 1 at different concentration, $0.12 \mathrm{mM}$ (black), $0.17 \mathrm{mM}$ (blue), $0.22 \mathrm{mM}$ (orange), and $0.32 \mathrm{mM}$ (purple) in $\mathrm{O}_{2}$-saturated $\mathrm{MeCN}+1 \mathrm{M}$ $\mathrm{AcOH} .{ }^{35}$ (b) Plot for logarithm of $k_{a p}$, as estimated from the FOWA versus the logarithm of catalyst concentration and fitted linearly. The slope of the linear fit, 1.7, indicates a primarily second-order ORR process with respect to the catalyst.

\section{Heterogeneous Electrochemical ORR Studies}

\section{CV studies under $\mathrm{N}_{2}$}

To investigate the heterogeneous electrochemical activity of our $\mathbf{1}$ toward ORR, we immobilized our molecular catalyst by drop-casting onto the EPG electrodes using the methodology as described in the literature ${ }^{22,23}$ (see Experimental section). All the electrochemical experiments for heterogeneous ORR were studied in $1 \mathrm{M} \mathrm{H}_{2} \mathrm{SO}_{4}$ aqueous solution at $\mathrm{pH} 0$ after saturating with either $\mathrm{N}_{2}$ or $\mathrm{O}_{2}$. CVs collected for 1 adsorbed onto EPG surface in $\mathrm{N}_{2}$-saturated aqueous electrolyte showed a quasi-reversible redox wave centered at $0.63 \mathrm{~V}$ vs. NHE with the peak separation of $89 \mathrm{mV}$, could be attributed to the $\mathrm{Pd}^{\mathrm{III} / \mathrm{II}}$ redox couple (Figure 11a). The 
reversibility at the $\mathrm{Pd}^{\mathrm{IIIII}}$ redox wave became more prominent as the scan rate was increased up to $5 \mathrm{~V} / \mathrm{s}$, and peak current densities obtained for $\mathrm{Pd}^{\mathrm{III} / \mathrm{II}}$ redox couples at different scan rates showed a linear correlation with the scan rate (Figure 11b), indicating the efficient immobilization of the catalyst onto the surface. ${ }^{23,29}$ Peak current densities for this reversible wave were stable upon repeating CV sweeps (Figure 12, blue), and the electroactive species adsorbed onto the surface of the electrode, $\Gamma=\left(Q_{C V} / n F A\right)$ was estimated as $1.65 \times 10^{-10} \mathrm{~mol} / \mathrm{cm}^{2}$ by considering $Q_{C V}(1.44 \mu \mathrm{C})$ as the charge passed at the reductive $\mathrm{Pd}^{\mathrm{IIIIII}}$ wave in $\mathrm{N}_{2}$-saturated aqueous electrolyte, $\mathrm{n}$ is the number of electrons (equal to 1 for the $\mathrm{Pd}^{\mathrm{III} / \mathrm{II}}$ couple), $\mathrm{F}$ is the Faraday constant, and $\mathrm{A}$ is the surface of the EPG electrode $\left(0.09 \mathrm{~cm}^{2}\right){ }^{40}$
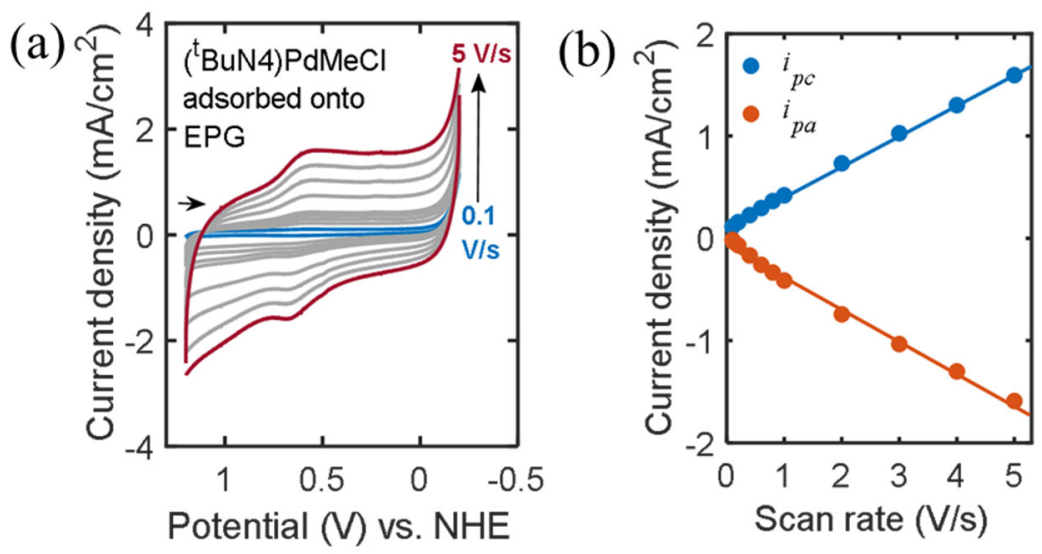

Figure 11. (a) CVs recorded for 1 adsopbed onto EPG in $\mathrm{N}_{2}$-saturated $1 \mathrm{M} \mathrm{H}_{2} \mathrm{SO}_{4}$ aqueous solution at different scan rates $(0.1 \mathrm{~V} / \mathrm{s}-5 \mathrm{~V} / \mathrm{s})$. (b) Peak currents obtained for $\mathrm{Pd}^{\mathrm{II} / \mathrm{III}}$ redox couple were plotted versus the scan rate $(\mathrm{V} / \mathrm{s})$.

\section{CV studies under $\mathrm{O}_{2}$}

The CVs collected for 1 immobilized onto the EPG electrode in $\mathrm{O}_{2}$-saturated acidic medium showed a ca. 5-fold current enhancement at $0.03 \mathrm{~V}$ vs. NHE when compare to CVs recorded under $\mathrm{N}_{2}$ (Figure 12). The peak currents observed for surface deposited $\mathbf{1}$ showed no current degradation in the presence of $\mathrm{O}_{2}$ when subsequent $\mathrm{CV}$ cycles were collected under 
identical electrochemical conditions (Figure 12). Noteworthy, the peak potential observed for $\mathbf{1}$ adsorbed onto the EPG electrode was $270 \mathrm{mV}$ more positive than that of the bare EPG electrode in $\mathrm{O}_{2}$-sparged $1 \mathrm{M} \mathrm{H}_{2} \mathrm{SO}_{4}$ aqueous solution (Figure $\mathrm{S} 26$ ).

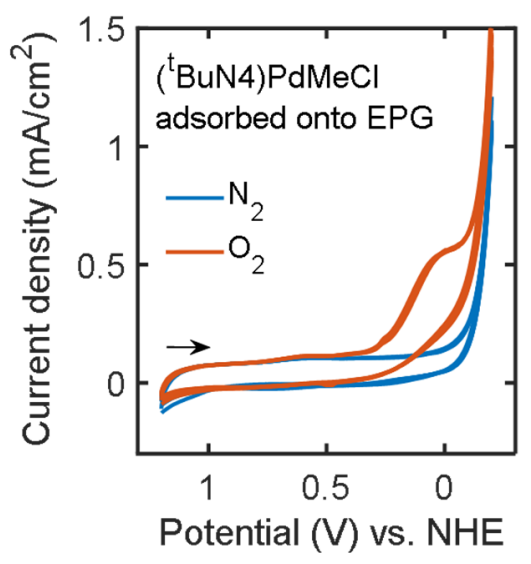

Figure 12. Comparative CVs recorded for 1 immobilized onto EPG surface in (blue) $\mathrm{N}_{2}$ - and (orange) $\mathrm{O}_{2}$-saturated $1 \mathrm{M} \mathrm{H}_{2} \mathrm{SO}_{4}$ aqueous solution ( $\mathrm{pH}$ 0) upon four repeating $\mathrm{CV}$ sweeps. All CVs were recorded at $0.1 \mathrm{~V} / \mathrm{s}$ scan rate. The arrow shown in the figure indicates the direction of these CV scans.

\section{Rotating-ring disk electrode (RRDE) voltammetry for heterogeneous ORR}

The selectivity of $\mathbf{1}$ toward heterogeneous electrochemical $\mathrm{O}_{2}$ reduction was also studied by carrying out RRDE experiments after drop-casting the catalyst onto a glassy carbon (GC) disk using $0.1 \%$ weight equivalent of Nafion as an adhesive. An unmodified Pt-ring electrode was used in the RRDE experiments, and the potential of the Pt-ring was kept fixed at $1.0 \mathrm{~V}$ vs. reference electrode to make sure that all $\mathrm{O}_{2}$-reduced species will be oxidized back to $\mathrm{O}_{2}$. The $\mathrm{RRDE}$ results obtained for 1 immobilized on the $\mathrm{GC}$ disk in $\mathrm{O}_{2}$-saturated $1 \mathrm{M} \mathrm{H}_{2} \mathrm{SO}_{4}$ solution showed quasilimiting disk currents at potentials lower than $0.3 \mathrm{~V}$ vs. NHE, and such currents increased with the rotation rates of the disk electrodes (Figure 13a). While the onset potentials for these disk currents did not match exactly the potentials observed in the CVs recorded for $\mathbf{1}$ immobilized onto the EPG electrode in the $\mathrm{O}_{2}$-saturated aqueous medium (Figure 12), we assigned these differences to the 
different carbon surfaces used in the cyclic voltammetry and RRDE experiments, the EPG electrodes and GC disk with nafion as adhesive, respectively, which could effect the degree of immobilization of 1 onto the surface of electrodes, and hence the onset potentials. However, 1 showed comparatively low ring currents in $\mathrm{O}_{2}$-saturated aqueous electrolyte under the same electrochemical conditions, suggesting higher selectivity for $\mathrm{O}_{2}$ reduction toward $\mathrm{H}_{2} \mathrm{O}$ formation. The Faradaic efficiency (FE) for $\mathrm{H}_{2} \mathrm{O}$ was then calculated at different rotation rates using the Eq. (2). When catalyst 1 was immobilized onto the GC disk electrode, an $80 \% \mathrm{FE}$ for $\mathrm{H}_{2} \mathrm{O}$ formation was observed at the rotation rate of $150 \mathrm{rpm}$ and applied potentials lower than $0.3 \mathrm{~V}$ during the ORR electrocatalysis in acidic aqueous electrolyte, and the percentage of $\mathrm{H}_{2} \mathrm{O}$ formation increased up to $\sim 90 \%$ when the rotation of the RRDE electrode was increased up to $700 \mathrm{rpm}$ (Figure 13b). Although even under optimal conditions for electrochemical ORR catalyzed by the Pd complex $\mathbf{1}$, a small amount of $\mathrm{H}_{2} \mathrm{O}_{2}$ is still formed, which is not desirable when designing practical energy devices, the finding that a surprisingly stable high-valent organometallic $\mathrm{Pd}^{\mathrm{III}}$ complex can serve as a heterogeneous catalyst for ORR under a very acidic ( $\mathrm{pH} 0)$ aqueous environment medium, without any notable catalyst decomposition while reducing $\mathrm{O}_{2}$ in water, is deemed to be quite unique. Detailed studies aimed at understanding the identity of complex 1 upon immobilization onto the electrode surface will be focus of our future research efforts. 

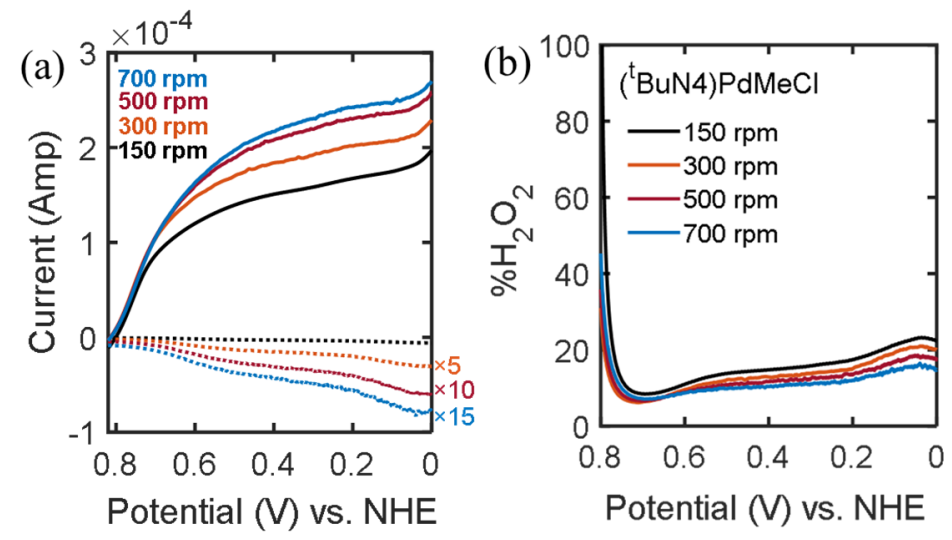

Figure 13. (a) RRDE data for 1 immobilized on a glassy carbon disk in $\mathrm{O}_{2}$-saturated $1 \mathrm{M} \mathrm{H}_{2} \mathrm{SO}_{4}$ solution at different rotation rates $(\omega) ; 150 \mathrm{rpm}$ (black), $300 \mathrm{rpm}$ (orange), $500 \mathrm{rpm}$ (magenta), 700 rpm (blue). The ring currents obtained at $300 \mathrm{rpm}, 500 \mathrm{rpm}$, and $700 \mathrm{rpm}$ are magnified by 5, 10, and 15 times, respectively, for clarity. Scan rate $=0.02 \mathrm{~V} / \mathrm{s}$. The potential for Pt-ring was held at $1 \mathrm{~V}$ vs. reference electrode. (b) The Faradaic efficiencies (FE) for $\mathrm{H}_{2} \mathrm{O}_{2}\left(\% \mathrm{H}_{2} \mathrm{O}_{2}\right)$ were calculated from (a) using Eq. (2). $\% \mathrm{H}_{2} \mathrm{O}=100-\% \mathrm{H}_{2} \mathrm{O}_{2}$.

\section{Koutecky-Levich plots and ORR kinetics}

To calculate the number of electrons involved in heterogeneous ORR using our catalyst, the Koutecky-Levich (K-L) plots, $i_{\text {lim }}^{-1}$ versus $\omega^{-1 / 2}$, were constructed, where $i_{\text {lim }}$ is the limiting disk currents observed for our catalyst immobilized disk electrode at a given angular rotation rate ( $\omega$, Figure 14). For a better comparison, we have also included the theoretical K-L plots corresponding to $2 \mathrm{e}^{-}$and $4 \mathrm{e}^{-}$events of the ORR process. The linear fit of the experimental K-L plot for 1 adsorbed EPG at the applied potential of $0.1 \mathrm{~V}$ vs. NHE is parallel to the theoretical KL plot of the number of electrons, $\mathrm{n}=4$, suggest a $4 \mathrm{e}^{-}$reduction of $\mathrm{O}_{2}$ to $\mathrm{H}_{2} \mathrm{O}$. The number of electrons associated with the ORR process $\left(n_{\exp }\right)$ for the heterogeneous catalyst $\mathbf{1}$ was also extracted from the slope of the experimental K-L plots and found to be 4.03 at an applied potential of 0.1 V vs. NHE (Figure 14), while a range of $n_{\exp }$ of $3.74-4.03$ was found considering the quasilimiting disk currents within the potential window between $0.2 \mathrm{~V}$ and $0.1 \mathrm{~V}$ vs. NHE (Figure 
S28b). Moreover, the intercepts obtained from the linearly fitted experimental K-L plots were used to estimate the overall second-order reaction rate constant, $k_{\text {cat }}$ for our heterogeneous ORR catalyst $\mathbf{1}$, and found to be $1.26 \times 10^{5} \mathrm{M}^{-1} \mathrm{~s}^{-1}$.

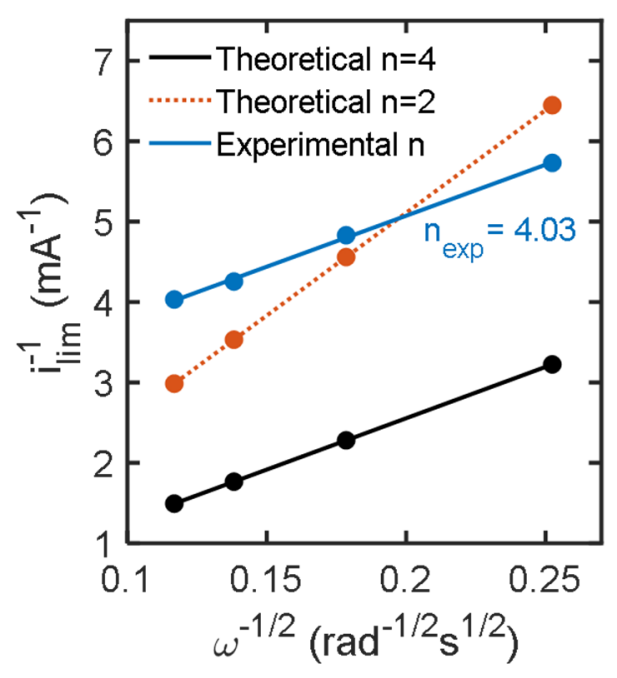

Figure 14. Koutecky-Levich (K-L) plots for $\mathbf{1}$ adsorbed onto a rotating carbon disk electrode considering the limiting currents observed at $0.1 \mathrm{~V}$ (blue), and the theoretical K-L plots for $2 \mathrm{e}^{-}$ (orange) and $4 \mathrm{e}^{-}$(black) processes are shown for comparison. $n_{\text {Exp }}$ is the number of electrons involved in the ORR process estimated from the slope of the K-L plot for $\mathbf{1 .}$

\section{Standard potentials and overpotential analysis}

To benchmark the thermodynamic parameters obtained for homogeneous and heterogeneous ORR using 1 in $\mathrm{MeCN}$ and aqueous solutions, respectively, we first calculated the standard potential $\left(E_{\mathrm{O}_{2} / \mathrm{H}_{2} \mathrm{O}(\mathrm{MeCN})}^{0}\right)$ for the $4 \mathrm{H}^{+} / 4 \mathrm{e}^{-}$reduction of $\mathrm{O}_{2}$ in $\mathrm{MeCN}$ in the presence of $\mathrm{AcOH}$ using Eq. (3). ${ }^{41}$ Considering the $\mathrm{p} K_{\mathrm{a}}$ of $\mathrm{AcOH}$ in $\mathrm{MeCN}$ as $23.51,{ }^{34}$ we obtained $E_{\mathrm{O}_{2} / \mathrm{H}_{2} \mathrm{O}(\mathrm{MeCN})}^{0}=-0.182 \mathrm{~V}$ vs. $\mathrm{Fc}^{+/ 0}$. However, the standard potential for the same redox reaction in aqueous medium is $+1.23 \mathrm{~V}$ vs. $\mathrm{NHE}^{42}$ that can be referenced as $+0.59 \mathrm{~V}$ vs. $\mathrm{Fc}^{+/ 0}$, by subtracting $-0.64 \mathrm{~V}$ according to Eq. (4). ${ }^{30}$

$$
\mathrm{O}_{2(\mathrm{~g})}+4 \mathrm{H}_{(\mathrm{MeCN})}^{+}+4 \mathrm{e}_{(\mathrm{MeCN})}^{-} \rightleftharpoons 2 \mathrm{H}_{2} \mathrm{O}_{(\mathrm{MeCN})}
$$


$E_{\mathrm{O}_{2} / \mathrm{H}_{2} \mathrm{O}(\mathrm{MeCN})}^{0}=1.21 \mathrm{~V}-0.0592 \times p K_{a, \mathrm{MeCN}}^{\mathrm{ACOH}}=-0.182 \mathrm{~V}$ vs. $\mathrm{Fc}^{+/ 0}$

Eq. (3)

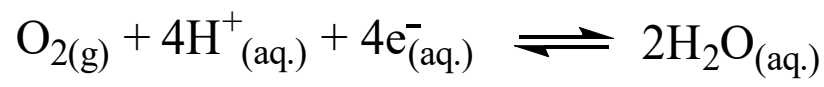

$E_{\mathrm{O}_{2} / \mathrm{H}_{2} O(M e C N)}^{0}=1.23 \mathrm{~V}(\mathrm{vs} . \mathrm{NHE})-0.64 \mathrm{~V}=0.59 \mathrm{~V}$ vs. $\mathrm{Fc}^{+/ 0}$;

Eq. (4)

Considering these standard potentials (vs. $\mathrm{Fc}^{+/ 0}$ ) for the reduction of $\mathrm{O}_{2}$ to water in $\mathrm{MeCN}$ and aqueous electrolyte, we then estimated the overpotentials for the ORR catalyzed by 1 within the applied potential $\left(E_{\text {applied }}\right)$ between the onset $\left(E_{\text {onset }}\right)$ and the catalytic peak potential $\left(E_{\text {cat }}\right.$, Figure 15). For the homogeneous case, 1 exhibited an overpotential $\left(E_{\mathrm{O}_{2} / \mathrm{H}_{2} \mathrm{O}(\mathrm{MeCN})}^{0}-E_{\text {applied }}\right)$ within the range of $0.32 \mathrm{~V}$ and $0.82 \mathrm{~V}$ (Figure 15, top). By contrast, the estimated overpotential $\left(E_{O_{2} / H_{2} O(\text { aqueous })}^{0}-E_{\text {applied }}\right)$ for $\mathbf{1}$ immobilized onto the EPG electrode is comparatively much higher and in between $0.77 \mathrm{~V}$ and $1.3 \mathrm{~V}$ (Figure 15, bottom). The rationale to support the lessthan-optimal thermochemistry obtained for $\mathbf{1}$ in the heterogeneous case is not known at this time, since the nature of the adsorbed catalyst still needs to be better characterized.

Homogeneous case in MeCN electrolyte:

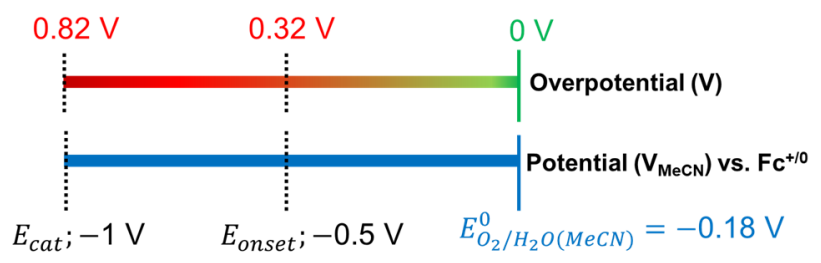

Heterogeneous case in aqueous electrolyte:

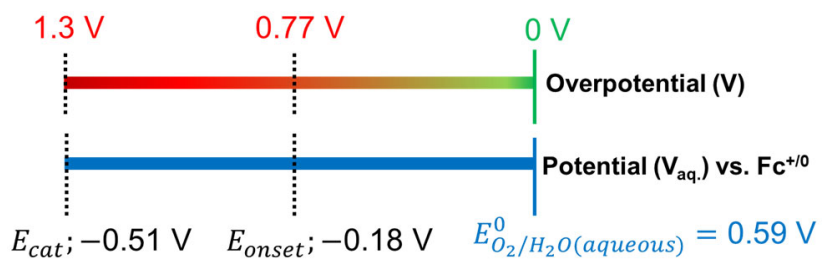

Figure 15. Calculated diagrams for 1 to estimate the overpotentials involved in homogeneous (top) and heterogeneous (bottom) ORR processes in $0.1 \mathrm{M} \mathrm{TBAPF} / \mathrm{MeCN}$ and $1 \mathrm{M} \mathrm{H}_{2} \mathrm{SO}_{4}$ aqueous 
solution ( $\mathrm{pH}$ ), respectively. The potential windows for both cases are referenced versus $\mathrm{Fc}^{+/ 0}$ for a better comparison.

\section{CONCLUSIONS}

In conclusion, herein we report an organometallic $\mathrm{Pd}^{\mathrm{III}}$ complex, [( $\left.\left.{ }^{\mathrm{t}} \mathrm{BuN} 4\right) \mathrm{Pd}^{\mathrm{III}} \mathrm{MeCl}\right] \mathrm{PF}$, $\mathbf{1} \cdot \mathbf{P F}_{\mathbf{6}}$, as a molecular and heterogeneous ORR catalyst in organic and aqueous medium using graphite electrodes that are earth-abundant and less expensive than the typical Pt-based cathode catalysts commonly used in fuel cells. The homogeneous and heterogeneous ORR reactivity of $\mathbf{1} \cdot \mathbf{P F}_{6}$ was studied in detail, and its reactivity was benchmarked for the selective reduction of $\mathrm{O}_{2}$ to $\mathrm{H}_{2} \mathrm{O}$. This complex exhibited elevated ORR kinetics in the $\mathrm{MeCN}$ solution in the presence of $\mathrm{AcOH}$ at low overpotential $(0.32 \mathrm{~V})$ to the onset potential. Analysis of electrochemical data suggests the formation of a binuclear $\mathrm{Pd}^{\mathrm{III}}$ intermediate in solution, likely a Pd ${ }^{\mathrm{III}}$-peroxo-PdII species, which dictates the thermochemistry of the ORR process for $\left[\left({ }^{t} \mathrm{BuN} 4\right) \mathrm{Pd}{ }^{\mathrm{III}} \mathrm{MeCl}\right]^{+}$in $\mathrm{MeCN}$, and thus being a rare example of a bimolecular ORR process. The selectivity for $\mathrm{H}_{2} \mathrm{O}$ production under these homogeneous ORR conditions was investigated using hydrodynamic electrochemical methods, and the $\mathrm{FE}$ for $\mathrm{H}_{2} \mathrm{O}$ formation was as high as $70 \%$. Furthermore, the immobilization of the molecular Pd ${ }^{\mathrm{III}}$ ORR electrocatalyst onto graphite electrodes led to the reduction of $\mathrm{O}_{2}$ in acidic aqueous solution with a $\mathrm{FE}$ greater than $80 \%$ for $\mathrm{H}_{2} \mathrm{O}$ formation. Although the overpotential observed for heterogeneous case is comparatively high, the performance of an organometallic $\mathrm{Pd}^{\mathrm{III}}$ complex toward $\mathrm{O}_{2}$ reduction under strong acidic conditions is impressive in terms of its catalytic stability, selectivity, and turnover number. This uncommon stability of the Pd complex 1•PF $\mathbf{6}$ under reducing conditions and the lack of any Pd metal deposition is unique and likely due to the hard donor atoms of the ${ }^{\mathrm{t}} \mathrm{BuN} 4$ ligand and the presence of an organic methyl 
ligand that severely destabilize the low oxidation states of the Pd center. Overall, these studies suggest that organometallic molecular Pd catalysts could be potentially used in paired electrolysis applications to couple the ORR with oxidative organometallic transformations of interest to the chemical and petroleum industry.

ASSOCIATED CONTENT

AUTHOR INFORMATION

\section{Corresponding Author}

Liviu M. Mirica - Department of Chemistry, University of Illinois at Urbana-Champaign, 600 S.

Mathews Avenue, Urbana, IL, 61801, USA.

Email: mirica@illinois.edu

\section{Author}

Soumalya Sinha - Department of Chemistry, University of Illinois-Urbana Champaign, $600 \mathrm{~S}$.

Mathews Avenue, Urbana, IL, 61801, USA.

\section{ORCID}

Liviu M. Mirica: 0000-0003-0584-9508

Soumalya Sinha: 0000-0002-6212-1102

\section{Author Contributions}

The manuscript was written through the contributions of all authors. All authors have given approval to the final version of the manuscript.

\section{Notes}

The authors declare no competing financial interest. 


\section{ACKNOWLEDGMENTS}

We thank the University of Illinois for supporting the initial studies described herein. We acknowledge Prof. Andrew A. Gewirth and Prof. Joaquín Rodríguez-López and their research groups for allowing us access to their rotating-ring disk electrode setups. We also thank Prof. Jeffrey J. Warren for providing us the edge plane graphite electrodes.

\section{REFERENCES}

1. Behling, N. H. In Fuel Cells; Behling, N. H., Ed.; Elsevier, 2013; p. 7.

2. Winter, M.; Brodd, R. J. What Are Batteries, Fuel Cells, and Supercapacitors? Chem. Rev. 2004, 104, 4245.

3. Lewis, N. S.; Nocera, D. G. Powering the planet: Chemical challenges in solar energy utilization Proc. Nat. Acad. Sci. USA 2006, 103, 15729.

4. Devivaraprasad, R.; Nalajala, N.; Bera, B.; Neergat, M. Electrocatalysis of Oxygen Reduction Reaction on Shape-Controlled Pt and Pd Nanoparticles-Importance of Surface Cleanliness and Reconstruction Frontiers in Chemistry 2019, 7.

5. Borup, R.; Meyers, J.; Pivovar, B.; Kim, Y. S.; Mukundan, R.; Garland, N.; Myers, D.; Wilson, M.; Garzon, F.; Wood, D.; Zelenay, P.; More, K.; Stroh, K.; Zawodzinski, T.; Boncella, J.; McGrath, J. E.; Inaba, M.; Miyatake, K.; Hori, M.; Ota, K.; Ogumi, Z.; Miyata, S.; Nishikata, A.; Siroma, Z.; Uchimoto, Y.; Yasuda, K.; Kimijima, K.-i.; Iwashita, N. Scientific Aspects of Polymer Electrolyte Fuel Cell Durability and Degradation Chem. Rev. 2007, 107, 3904.

6. Dey, S.; Mondal, B.; Chatterjee, S.; Rana, A.; Amanullah, S.; Dey, A. Molecular electrocatalysts for the oxygen reduction reaction Nature Reviews Chemistry 2017, 1, 0098.

7. Mittermeier, T.; Weiß, A.; Gasteiger, H. A.; Hasché, F. Monometallic Palladium for Oxygen Reduction in PEM Fuel Cells: Particle-Size Effect, Reaction Mechanism, and Voltage Cycling Stability J. Electrochem. Soc. 2017, 164, F1081.

8. Siebel, A.; Gorlin, Y.; Durst, J.; Proux, O.; Hasché, F.; Tromp, M.; Gasteiger, H. A. Identification of Catalyst Structure during the Hydrogen Oxidation Reaction in an Operating PEM Fuel Cell ACS Catal. 2016, 6, 7326.

9. Durst, J.; Simon, C.; Hasché, F.; Gasteiger, H. A. Hydrogen Oxidation and Evolution Reaction Kinetics on Carbon Supported Pt, Ir, Rh, and Pd Electrocatalysts in Acidic Media $J$. Electrochem. Soc. 2014, 162, F190.

10. Stonehart, P. Electrocatalyst advances for hydrogen oxidation in phosphoric acid fuel cells Int. J. Hydrogen Energy 1984, 9, 921. 
11. Nørskov, J. K.; Rossmeisl, J.; Logadottir, A.; Lindqvist, L.; Kitchin, J. R.; Bligaard, T.; Jónsson, H. Origin of the Overpotential for Oxygen Reduction at a Fuel-Cell Cathode The Journal of Physical Chemistry B 2004, 108, 17886.

12. Zhang, J.; Vukmirovic, M. B.; Xu, Y.; Mavrikakis, M.; Adzic, R. R. Controlling the Catalytic Activity of Platinum-Monolayer Electrocatalysts for Oxygen Reduction with Different Substrates Angew. Chem., Int. Ed. 2005, 44, 2132.

13. Yang, J.; Lee, J. Y.; Zhang, Q.; Zhou, W.; Liu, Z. Carbon-Supported Pseudo-Core-Shell PdPt Nanoparticles for ORR with and without Methanol J. Electrochem. Soc. 2008, 155, B776.

14. Oezaslan, M.; Hasché, F.; Strasser, P. Pt-Based Core-Shell Catalyst Architectures for Oxygen Fuel Cell Electrodes The Journal of Physical Chemistry Letters 2013, 4, 3273.

15. Cherevko, S.; Zeradjanin, A. R.; Topalov, A. A.; Kulyk, N.; Katsounaros, I.; Mayrhofer, K. J. J. Dissolution of Noble Metals during Oxygen Evolution in Acidic Media Chemcatchem 2014, 6, 2219.

16. Grdeń, M.; Łukaszewski, M.; Jerkiewicz, G.; Czerwiński, A. Electrochemical behaviour of palladium electrode: Oxidation, electrodissolution and ionic adsorption Electrochim. Acta 2008, 53, 7583.

17. Pizzutilo, E.; Geiger, S.; Freakley, S. J.; Mingers, A.; Cherevko, S.; Hutchings, G. J.; Mayrhofer, K. J. J. Palladium electrodissolution from model surfaces and nanoparticles Electrochim. Acta 2017, 229, 467.

18. Pegis, M. L.; Wise, C. F.; Martin, D. J.; Mayer, J. M. Oxygen Reduction by Homogeneous Molecular Catalysts and Electrocatalysts Chem. Rev. 2018, 118, 2340.

19. Passard, G.; Dogutan, D. K.; Qiu, M.; Costentin, C.; Nocera, D. G. Oxygen Reduction Reaction Promoted by Manganese Porphyrins ACS Catal. 2018, 8, 8671.

20. Carver, C. T.; Matson, B. D.; Mayer, J. M. Electrocatalytic Oxygen Reduction by Iron Tetraarylporphyrins Bearing Pendant Proton Relays J. Am. Chem. Soc. 2012, 134, 5444.

21. Matson, B. D.; Carver, C. T.; Von Ruden, A.; Yang, J. Y.; Raugei, S.; Mayer, J. M. Distant protonated pyridine groups in water-soluble iron porphyrin electrocatalysts promote selective oxygen reduction to water Chem. Comm. 2012, 48, 11100.

22. Sinha, S.; Aaron, M. S.; Blagojevic, J.; Warren, J. J. Electrocatalytic Dioxygen Reduction by Carbon Electrodes Noncovalently Modified with Iron Porphyrin Complexes: Enhancements from a Single Proton Relay Chem. Eur. J. 2015, 21, 18072.

23. Sinha, S.; Ghosh, M.; Warren, J. J. Changing the Selectivity of O2 Reduction Catalysis with One Ligand Heteroatom ACS Catal. 2019, 9, 2685.

24. Zhang, R.; Warren, J. J. Controlling the Oxygen Reduction Selectivity of Asymmetric Cobalt Porphyrins by Using Local Electrostatic Interactions J. Am. Chem. Soc. 2020, 142, 13426.

25. Khusnutdinova, J. R.; Rath, N. P.; Mirica, L. M. Stable Mononuclear Organometallic Pd(III) Complexes and Their C-C Bond Formation Reactivity J. Am. Chem. Soc. 2010, 132, 7303.

26. Khusnutdinova, J. R.; Rath, N. P.; Mirica, L. M. The Aerobic Oxidation of a Pd(II) Dimethyl Complex Leads to Selective Ethane Elimination from a $\mathrm{Pd}(\mathrm{III})$ Intermediate $\mathrm{J}$. Am. Chem. Soc. 2012, 134, 2414. 
27. Tang, F.; Zhang, Y.; Rath, N. P.; Mirica, L. M. Detection of Pd(III) and Pd(IV) Intermediates during the Aerobic Oxidative C-C Bond Formation from a $\mathrm{Pd}(\mathrm{II})$ Dimethyl Complex Organometallics 2012, 31, 6690.

28. Schultz, J. W.; Rath, N. P.; Mirica, L. M. Improved Oxidative C-C Bond Formation Reactivity of High-Valent Pd Complexes Supported by a Pseudo-Tridentate Ligand Inorg. Chem. 2020, 59, 11782.

29. Elgrishi, N.; Rountree, K. J.; McCarthy, B. D.; Rountree, E. S.; Eisenhart, T. T.; Dempsey, J. L. A Practical Beginner's Guide to Cyclic Voltammetry J. Chem. Educ. 2018, 95, 197.

30. Pavlishchuk, V. V.; Addison, A. W. Conversion constants for redox potentials measured versus different reference electrodes in acetonitrile solutions at $25^{\circ} \mathrm{C}$ Inorg. Chim. Acta 2000, 298, 97.

31. Bard, A. J.; Faulkner, L. R. Electrochemical Methods: Fundamentals and Applications; 2nd ed.; Wiley, 2008.

32. O'Reilly, M. E.; Kim, R. S.; Oh, S.; Surendranath, Y. Catalytic Methane Monofunctionalization by an Electrogenerated High-Valent Pd Intermediate ACS Central Science 2017, 3, 1174.

33. Costentin, C.; Saveant, J. M. Multielectron, Multistep Molecular Catalysis of Electrochemical Reactions: Benchmarking of Homogeneous Catalysts Chemelectrochem 2014, 1, 1226.

34. McCarthy, B. D.; Martin, D. J.; Rountree, E. S.; Ullman, A. C.; Dempsey, J. L. Electrochemical Reduction of Brønsted Acids by Glassy Carbon in AcetonitrileImplications for Electrocatalytic Hydrogen Evolution Inorg. Chem. 2014, 53, 8350.

35. See Supporting Information.

36. Ngo, K. T.; McKinnon, M.; Mahanti, B.; Narayanan, R.; Grills, D. C.; Ertem, M. Z.; Rochford, J. Turning on the Protonation-First Pathway for Electrocatalytic CO2 Reduction by Manganese Bipyridyl Tricarbonyl Complexes J. Am. Chem. Soc. 2017, 139, 2604.

37. Dudkina, Y. B.; Mikhaylov, D. Y.; Gryaznova, T. V.; Tufatullin, A. I.; Kataeva, O. N.; Vicic, D. A.; Budnikova, Y. H. Electrochemical Ortho Functionalization of 2-Phenylpyridine with Perfluorocarboxylic Acids Catalyzed by Palladium in Higher Oxidation States Organometallics 2013, 32, 4785.

38. Costentin, C.; Drouet, S.; Robert, M.; Saveant, J. M. Turnover numbers, turnover frequencies, and overpotential in molecular catalysis of electrochemical reactions. Cyclic voltammetry and preparative-scale electrolysis J. Am. Chem. Soc. 2012, 134, 11235.

39. Chin, D.-H.; La Mar, G. N.; Balch, A. L. Mechanism of autoxidation of iron(II) porphyrins. Detection of a peroxo-bridged iron(III) porphyrin dimer and the mechanism of its thermal decomposition to the oxo-bridged iron(III) porphyrin dimer J. Am. Chem. Soc. 1980, 102, 4344.

40. Maurin, A.; Robert, M. Noncovalent Immobilization of a Molecular Iron-Based Electrocatalyst on Carbon Electrodes for Selective, Efficient CO2-to-CO Conversion in Water J. Am. Chem. Soc. 2016, 138, 2492. 
41. Machan, C. W. Advances in the Molecular Catalysis of Dioxygen Reduction ACS Catal. 2020, 10, 2640.

42. Pegis, M. L.; Roberts, J. A. S.; Wasylenko, D. J.; Mader, E. A.; Appel, A. M.; Mayer, J. M. Standard Reduction Potentials for Oxygen and Carbon Dioxide Couples in Acetonitrile and N,N-Dimethylformamide Inorg. Chem. 2015, 54, 11883. 
Table of Contents Graphic

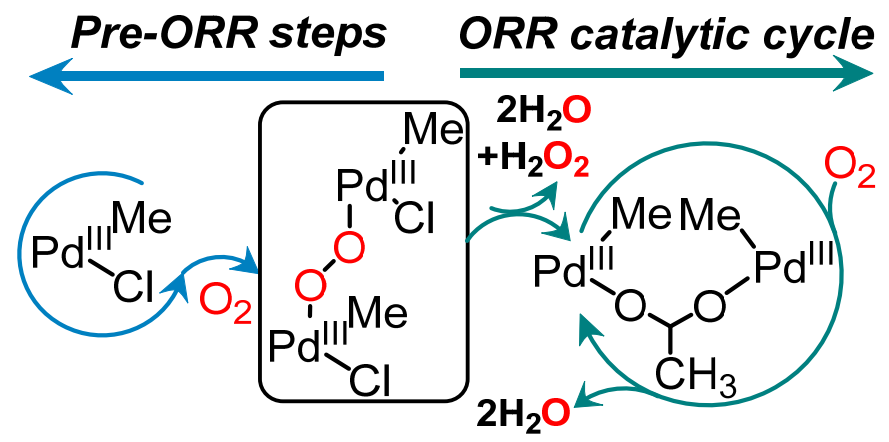

